Article

\title{
Anthocyanidins Inhibit Growth and Chemosensitize Triple-Negative Breast Cancer via the NF-кB Signaling Pathway
}

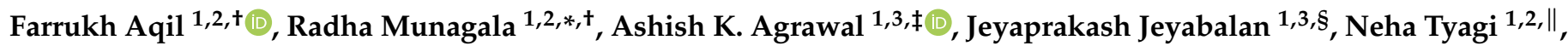 \\ Shesh N. Rai ${ }^{4}$ (I) and Ramesh C. Gupta ${ }^{1,3, *}$
}

1 UofL Health-Brown Cancer Center, 580 S. Preston St., Rm 304E, Baxter II Research Building, University of Louisville, Louisville, KY 40202, USA; farrukh.aqil@louisville.edu (F.A.); ashish.phe@iitbhu.ac.in (A.K.A.); jp3pbiotech@gmail.com (J.J.); neha.tyagi@tamu.edu (N.T.)

2 Department of Medicine, University of Louisville, Louisville, KY 40202, USA

3 Department of Pharmacology and Toxicology, 580 S. Preston St., Rm 304E, Baxter II Research Building, University of Louisville, Louisville, KY 40202, USA

4 Department of Biostatistics and Bioinformatics, University of Louisville, Louisville, KY 40202, USA; shesh.rai@louisville.edu

* Correspondence: radha.munagla@gmail.com (R.M.); rcgupta@louisville.edu (R.C.G.); Tel.: +1-502-852-3684 (R.M.); +1-502-852-3689 (R.C.G.); Fax: +1-502-852-3842 (R.M. \& R.C.G.)

+ Equal First Authors.

$\ddagger$ Current affiliation: Department of Pharmaceutical Engineering and Technology, Indian Institute of Technology Varanasi, Varanasi 221005, Uttar Pradesh, India.

$\S$ Current affiliation: 3P Biotechnologies, Inc., Louisville, KY 40202, USA.

|| Current affiliation: Department of Veterinary Pathobiology, College of Veterinary Medicine and Biological Sciences, Texas A\&M University, College Station, TX 77843, USA.

Citation: Aqil, F.; Munagala, R.; Agrawal, A.K.; Jeyabalan, J.; Tyagi, N.; Rai, S.N.; Gupta, R.C. Anthocyanidins Inhibit Growth and Chemosensitize Triple-Negative Breast Cancer via the NF- $\kappa B$ Signaling Pathway. Cancers 2021, 13, 6248. https://doi.org/ $10.3390 /$ cancers 13246248

Academic Editors: Martine Berliere and Christine C. Galant

Received: 2 November 2021

Accepted: 8 December 2021

Published: 13 December 2021

Publisher's Note: MDPI stays neutral with regard to jurisdictional claims in published maps and institutional affiliations.

Copyright: () 2021 by the authors. Licensee MDPI, Basel, Switzerland. This article is an open access article distributed under the terms and conditions of the Creative Commons Attribution (CC BY) license (https:// creativecommons.org/licenses/by/ $4.0 /)$.
Simple Summary: Breast cancer is the most common female cancer diagnosed in the U.S. and the second most common cause of cancer death in women. Chemotherapeutics used to treat breast cancer often have side effects, which are sometimes life-threatening. Moreover, the tumors can develop resistance over time, making breast cancer treatment challenging. In this paper, we show that the oral administration of colored pigments isolated from bilberry/blueberry, called anthocyanidins (Anthos), significantly decrease MDA-MB-231 orthoxenograft tumor volume, inhibit the growth and metastasis of breast cancer, sensitize drug-resistant tumor cells, and exhibit a lower rate of lymph node and lung metastasis, compared to control. Our results also suggest regulation of cell-cycle progression and inhibition of NF- $\mathrm{KB}$ activation as mechanisms underpinning the anti-proliferative activity of Anthos in breast cancer. These mechanistic insights are expected to be valuable for clinical translation of berry Anthos, either alone or as adjuvant to chemotherapy, for the treatment of breast cancer patients.

Abstract: Triple-negative breast cancer (TNBC) is an aggressive subtype of breast cancer. Due to the lack of drug-targetable receptors, chemotherapy is the only systemic treatment option. Although chemotherapeutic drugs respond initially in TNBC, many patients relapse and have a poor prognosis. Poor survival after metastatic relapse is largely attributed to the development of resistance to chemotherapeutic drugs. In this study, we show that bilberry-derived anthocyanidins (Anthos) can inhibit the growth and metastasis of TNBC and chemosensitize paclitaxel (PAC)-resistant TNBC cells by modulating the NF- $\mathrm{kB}$ signaling pathway, as well as metastatic and angiogenic mediators. Anthos administered orally significantly decreased MDA-MB-231 orthoxenograft tumor volume and led to lower rates of lymph node and lung metastasis, compared to control. Treatment of PACresistant MDA-MB-231Tx cells with Anthos and PAC in combination lowered the $\mathrm{IC}_{50}$ of PAC by nearly 20-fold. The combination treatment also significantly $(p<0.01)$ decreased the tumor volume in MDA-MB-231Tx orthoxenografts, compared to control. In contrast, Anthos and PAC alone were ineffective against MDA-MB-231Tx tumors. Our approach of using Anthos to inhibit the growth and metastasis of breast cancers, as well as to chemosensitize PAC-resistant TNBC, provides a highly promising and effective strategy for the management of TNBC. 
Keywords: breast cancer; anthocyanidins (Anthos); paclitaxel; chemosensitization; drug resistance; metastasis

\section{Introduction}

Breast cancer (BC) is the most common cancer in women, accounting for about $30 \%$ of female cancers, followed by lung cancer $(13 \%)$, with approximately 3.5 million BC survivors in the United States alone [1]. Despite advances in early detection and treatment modalities, metastasis is a great challenge in BC patients [2]. Approximately $90 \%$ of BC deaths are attributed to metastatic breast cancer (MBC), with an overall survival rate of only $22 \%$ [3]. Unlike the significant progress made in the prognosis of estrogen-responsive breast cancers, the prognosis for triple-negative breast cancer (TNBC) remains dismal.

TNBC is characterized by its unique molecular profile, aggressive nature, distinct metastatic patterns, and lack of targeted therapies, and accounts for $10-17 \%$ of all BC [4]. TNBC is characterized by a lack of estrogen receptor (ER), progesterone receptor (PR), and HER2 expression, and is particularly associated with an aggressive pathology [5]. Moreover, $20-40 \%$ of all BCs metastasize within 3 to 10 years following the original diagnosis, and approximately $90 \%$ of BC deaths are attributed to metastasis, with an overall survival rate of only $16 \%$ [6]. At present, the mainstay of treatment for patients diagnosed with TNBC is cytotoxic chemotherapy. Not only are the adjuvant treatments used for MBC that target hormone receptors ineffective for TNBC, but they may also increase resistance to conventional therapies, posing a great challenge for treatment.

Signal transduction pathways have been often considered as potential targets in elucidating the molecular mechanisms of small molecules, including phytochemicals. A new prospect in research to elucidate the mechanisms of potential anti-cancer compounds is the recent discovery of molecular links between inflammation and cancer [2]. Nuclear factor-kappaB (NF- $\mathrm{kB}$ ) is a ubiquitous redox-sensitive transcription factor that includes six family members and regulates a wide range of cellular events. It has been implicated in the pathogenesis of many inflammation-associated diseases. NF- $\kappa B$ binds to I $\kappa B \alpha$ and is sequestered in the cytoplasm. Phosphorylation mediated by the IкB kinase (IKK) complex and successive ubiquitination degrades $I \kappa B \alpha$ through the function of proteasomes. Due to their strong anti-inflammatory and antioxidant properties, Anthos have been proposed to demonstrate anti-cancer activity through the inhibition of NFKB-related pathways.

Resistance to chemotherapy is a major obstacle, and there are no standard practices for the effective management of MBC. The underlying biochemical and genetic causes of $\mathrm{MBC}$ resistance remain unclear. Over $80 \%$ of anti-tumor agents can be transported by ATP-binding cassette, which is frequently found to be elevated and may contribute to chemoresistance in BCs [7]. First-line chemotherapy provides only a 30-70\% response rate; however, many patients show relapse and require additional chemotherapy within 6 to 10 months. Regrettably, the response rates remain only around 20-30\% [8]. It is highly urgent that some unconventional new approaches be developed for the prevention and treatment of drug resistance and $\mathrm{MBC}$. A user-friendly strategy is to use a combination of efficacious natural non-toxic compounds along with standard chemotherapeutic drugs.

Berries and berry bioactives have begun to receive significant attention recently, due to their much higher antioxidant activity when compared with other common fruits and vegetables. Reports have indicated blueberry Anthos [6] as possessing antioxidant, antiinflammatory, anti-cancer, anti-diabetic, and cardio- and neuroprotective effects [9-14]. Several laboratories-including our own - have demonstrated their protective effect against carcinogen-induced cancers in animal models. A series of papers from the Stoner group initially showed that black raspberry and blackberry are effective against chemically induced colon [15] and esophageal [16] cancers. Preliminary results from a colon cancer clinical trial from the same groups have revealed $50 \%$ regression rates of rectal polyps [17]. Our series of studies have shown the significant inhibition of BC in an estrogen-sensitive 
ACI rat model by both blueberry and black raspberry [18-20], as well as for cigarette smoke-mediated lung cancer in a mouse model (our unpublished data), indicating that berries are chemopreventive beyond the GI tract. Berry bioactives also have significant therapeutic activity against lung [6], breast [21], ovarian [22], and colon cancer [23].

The chemopreventive and therapeutic activities of berries have been credited to the presence of colored pigments called anthocyanins. Berries in different parts of the world, such as blueberry in the U.S., bilberry in Europe, and jamun in Asia and South America, have been shown to contain glycosides of cyanidin (Cy), delphinidin (Dp), petunidin $(\mathrm{Pt})$, peonidin $(\mathrm{Pe})$, and malvidin $(\mathrm{Mv})$. The sugar-free counterparts of anthocyanins are anthocyanidins. A compelling body of literature has suggested that anthocyanidins have various pharmacological properties, including the inhibition of cancer cell growth in vitro and in vivo, the induction of apoptosis, and so on. Our studies against lung cancer have suggested that anthocyanidins present a higher degree of efficacy than anthocyanins. Furthermore, we have also shown a significant synergistic activity when using a combination of anthocyanidins, such as a native mixture isolated from bilberry, compared to individual entities [6].

In this manuscript, we investigate the anti-cancer activity of bilberry-derived Anthos against TNBC using MDA-MB-231 and MDA-MB-236 BC cells, both in vitro and in vivo. We also demonstrate the chemosensitization of drug-resistant $\mathrm{BC}$ cells by the Anthos in combination with the chemo drug, $\mathrm{PAC}$, and investigate the mechanism underlying the anti-cancer and anti-metastatic effects of the Anthos, with respect to the NF- $\mathrm{kB}$ signaling pathway, as well as metastatic and angiogenic mediators.

\section{Materials and Methods}

\subsection{Materials}

A native mixture of Anthos (>95\% pure) was isolated from a standardized highly enriched extract of bilberry using solvent extractions and C18 chromatography [24]. Bilberry (a European 'cousin' of blueberry) contains essentially the same anthocyanidin profile as blueberry. MTT (3-[4,5-dimethylthiazol-2-yl]-2,5-diphenyltetrazolium bromide) was purchased from Alfa Aesar (Ward Hill, MA, USA). RIPA cell lysis buffer, BCA protein assay kit, PVDF membranes, phosphate-buffered saline (PBS), ECL chemiluminescence reagent, and Bolt 4-12\% Bis-Tris phosphate gels were purchased from ThermoFisher (Rockford, IL, USA). Dulbecco's Modified Eagle's Medium (DMEM), L-15 media, penicillin, and streptomycin were purchased from Life Technologies (Gibco, Grand Islands, NY, USA). Fetal bovine serum (FBS) was purchased from ThermoFisher (Rockford, IL, USA). The human recombinant TGF $\beta-1$ (\#8915) and TNF $\alpha$ (\#8902) were purchased from Cell Signaling Technology (Danvers, MA, USA).

\subsection{Cell Culture}

BC cells, MDA-MB-231, MDA-MB-436, and HCC1937 were purchased from American Type Culture Collection (ATCC, Manassas, VA, USA). L-15 media was used to grow MDA-MB-231 and MDA-MB-236 cells, while HCC1937 was grown in McCoy's Medium supplemented with $10 \%$ fetal bovine serum and $1 \%$ antibiotics (penicillin/streptomycin). All cell lines were maintained at $37{ }^{\circ} \mathrm{C}$ in a humidified chamber at $5 \% \mathrm{CO}_{2}$, except for MDA-MB-231 and MDA-MB-436, which were grown without $\mathrm{CO}_{2}$.

\subsection{Anti-Proliferative Activity}

The anti-proliferative activity of the Anthos against various cancer cells was assessed by MTT assay, as described previously [6]. $\mathrm{IC}_{50}$ values were calculated using the CalcuSyn software Version 2.0 (Biosoft, Cambridge, UK).

\subsection{Flow Cytometry}

For apoptosis assays, MDA-MB-231, MDA-MB-236, and HCC1937 cells were treated with different concentrations of Anthos for 24-72 h. Post-treatment, cells were collected 
and stained with annexin V-FITC and PI, according to the manufacturer's guidelines (Invitrogen, Carlsbad, CA, USA). The cells were then evaluated for apoptosis by flow cytometry. The apoptotic cells were determined using a BD FACScan flow cytometer (Becton Dickinson, San Jose, CA, USA).

For cell cycle analysis, treated cells were fixed in ice-cold $70 \%$ ethanol for $30 \mathrm{~min}$ at $4{ }^{\circ} \mathrm{C}$, centrifuged again, and washed twice with PBS. The cells were resuspended in $1 \mathrm{~mL}$ of $20 \mu \mathrm{g} / \mathrm{mL}$ PI and $100 \mu \mathrm{g} / \mathrm{mL}$ RNase A in PBS, then incubated for $30 \mathrm{~min}$ at room temperature. DNA content was analyzed using a BD FACScan flow cytometer (Becton Dickinson, San Jose, CA, USA). The population of cells in each cell cycle phase was determined using the FlowJo software v7.2.5 (Treestar, Ashland, OR, USA).

\subsection{Wound Healing Assay}

The wound healing assay was performed using 2-well inserts from ibidi ${ }^{\circledR}$ (Munich, Germany) placed in 24-well plates, as described previously. Briefly, BC cells were suspended in culture media ( 100 cells $/ \mu \mathrm{L}$ ) and $100 \mu \mathrm{L}$ of the cell suspension was added to each of the two wells in the cell inserts. The cells were incubated for $24 \mathrm{~h}$ to allow for cell attachment, and then cell-free gaps (wounds) $1 \mathrm{~mm}$ wide were created by removing the culture inserts. The wells were then treated with various concentrations of Anthos. The wound areas were monitored by light microscopy at 0,24 , and $48 \mathrm{~h}$. At each of these time points, images of the wound areas were taken and quantified using the Wimasis Image Analysis software (WimScratch, Cordoba, Spain).

\subsection{Trans-Well Migration and Invasion Assays}

The trans-well migration and invasion assays were performed using uncoated and Matrigel-coated $8 \mu \mathrm{m}$ pore size trans-well chambers (BD Bioscience, San Jose, CA, USA), respectively. BC cells were treated with Anthos $(0-200 \mu \mathrm{M})$ in the presence or absence of TGF $\beta$ for $1 \mathrm{~h}$. For the migration assay, $4 \times 10^{4}$ cells were suspended in serum-free media and seeded into the top compartments of the trans-well chambers. Media supplemented with FBS as chemoattractant was added to the bottom chamber, to induce cell migration. After $24 \mathrm{~h}$, the migrated cells were fixed in $4 \%$ paraformaldehyde, permeabilized using $100 \%$ methanol, and stained using $0.2 \%$ toluidine blue. The number of migrated cells was counted in five random fields under a microscope. In the invasion experiment, the same procedure was performed by seeding $80 \times 10^{4}$ cells/well in Matrigel pre-coated trans-well chambers. Data are presented as representative microphotographs.

\subsection{Electrophoretic Mobility Shift Assay}

Analysis of NF- $\mathrm{KB}$ (DNA binding activity) was carried out through electrophoretic mobility shift assay (EMSA), as previously described [25]. The details are provided in the Supplementary Materials. DNA-protein complexes were visualized and quantified by Packard InstantImager (Packard Instruments, Downers Grove, IL, USA).

\subsection{Protein Extraction and Western Blot Analysis}

MDA-MB-231, MDA-MB-236, and HCC1937 cells were treated with various concentrations of Anthos for 24-72 h, and tumor tissues from an orthotopic breast cancer study were lysed in RIPA buffer containing protease inhibitor cocktail (Thermo Fisher Scientific, Waltham, MA, USA). Equal amounts of protein were separated by SDS-PAGE, and Western blot analysis was performed as described elsewhere [6,26]. Briefly, after transferring the proteins, the PVDF membrane was probed for the expression of specific proteins against various antibodies. The densities of each protein band, relative to the internal loading control ( $\beta$-actin), were quantified using the ImageJ software (NIH, Bethesda, MD, USA).

\subsection{Immunoprecipitation and IKK $\beta$ Kinase Activity Assay}

First, we immunoprecipitated IKK complexes from cell lysates using anti-IKK $\gamma$ antibodies (B-3) conjugated to agarose. Cell lysates (1-4 mg per sample) were incubated 
with antibodies (1-8 $\mathrm{mg}$ per sample) overnight at $4{ }^{\circ} \mathrm{C}$ under gentle rotation. Protein A Sepharose CL-4B beads (GE Healthcare Life Sciences; $10-30 \mu \mathrm{L}$ per sample) were added to the tubes and rotated at $4{ }^{\circ} \mathrm{C}$ for $1 \mathrm{~h}$. Beads were precipitated by centrifugation at $800 \times g$ for $30 \mathrm{~s}$ and washed three times with cold lysis buffer.

The in vitro IKK $\beta$ Kinase Activity assay was conducted with the harvested IKK complexes, using the Cyclex IKK Assay kit from MBL International (Woburn, MA, USA), following its instructions with no modifications.

Briefly, partially purified recombinant IKK $\beta$ and $10 \mu \mathrm{L}$ of each sample or standard was added to the assay plate on ice. IKK $\beta$-positive control (Cat\# CY-E1176-2) was included in each assay, as a positive control for phosphorylation. Kinase reaction buffer $(90 \mu \mathrm{L})$ was added to initiate the Kinase reaction and incubated for $30 \mathrm{~min}$ at $30{ }^{\circ} \mathrm{C}$. The wells were washed four times with wash buffer (containing $2 \%$ Tween-20). Residual wash buffer was removed by gentle tapping. Next, $100 \mu \mathrm{L}$ of Anti-phospho-IkBa serine 32 monoclonal antibody (AS-2E8) was pipetted into each well and incubated for $30 \mathrm{~min}$ at RT. Wells were washed five times. Later, $100 \mu \mathrm{L}$ of HRP-conjugated anti-mouse IgG was pipetted into each well and incubated for $30 \mathrm{~min}$ at RT. The wells were then washed five times again. Then, $100 \mu \mathrm{L}$ of Substrate Reagent (containing chromogenic substrate, tetra-methylbenzidine; TMD) was added to each well and incubated for 5-15 min at RT. Finally, $100 \mu \mathrm{L}$ of Stop Solution (containing 1NH2SO4) was added to each well. The absorbent signal in each well was measured with a spectrophotometric plate reader at dual 450/540 nm. All samples and standards were assayed in duplicate.

\subsection{RT-PCR Analysis}

Total RNA was isolated from cells using Trizol reagent (Invitrogen, Carlsbad, CA, USA). RNA samples (50 ng) were reverse transcribed and amplified using the Power SYBR Green RNA to CT 1-Step Kit according to the manufacturer's guidelines (Applied Biosystems, Waltham, MA, USA). The relative mRNA expression levels of MDR-related molecules, such as MRP1, MDR1, MRCP, and MVP, normalized to GAPDH or $\beta$-actin, were determined. The fold change for each sample was determined using the $2^{-\Delta \Delta \mathrm{Ct}}$ relative quantification method.

\subsection{Animal Studies}

The animal care and treatments were carried out in strict accordance with the protocol approved by the Institutional Animal Care and Use Committee (IACUC) of the University of Louisville.

A pilot study was launched to establish the orthotopic tumor xenografts of MDAMB-231, MDA-MB-236, and HCC1937 cells, in order to identify the optimal model for anti-tumor activity studies. Five- to six-week old Athymic nude mice and NOD-Scid mice were randomized into 6 groups $(n=4)$. Exponentially growing cells were detached by trypsinization, washed, and re-suspended in serum-free media. Cell suspensions $\left(2.5 \times 10^{6}\right)$ were mixed (at 1:1 volume) with Matrigel (BD Bioscience, Bedford, MA, USA) and injected under the second inguinal nipple on the right ventral side of the mammary pad. Animals were provided an AIN-93M purified diet and water ad libitum. Tumor volume, diet consumption, and animal health were monitored weekly. When tumors grew to $800 \mathrm{~mm}^{3}$, all animals were euthanized, and blood and tumor tissues were collected. To determine whether the orthotopic tumor xenografts resulted in distant metastasis, a gross examination of lymph nodes was conducted at the end of the study. Lymph nodes were collected at the time of euthanasia, and their size was calculated to examine the metastasis. Only MDA-MB-231 showed exponential growth of tumors and was also found to be highly metastatic; hence, they were chosen for the subsequent anti-tumor activity study.

For the anti-tumor activity study, $2.5 \times 10^{6} \mathrm{MDA}-\mathrm{MB}-231$ cells were injected under the second inguinal nipple on the right ventral side of the mammary pad, as described above. When the tumor grew to $120 \mathrm{~mm}^{3}$, animals were divided into three groups $(n=10-12)$ and treated with Anthos. Group 1 received vehicle control, whereas Groups 2 and 3 received 
the Anthos at $30 \mathrm{mg} / \mathrm{kg}$ and $60 \mathrm{mg} / \mathrm{kg}$, respectively, by oral gavage three times a week. When tumor volume in the control group reached $800 \mathrm{~mm}^{3}$, all animals were euthanized. Blood and selected tissues were collected. At euthanasia, we examined for gross metastasis of lymph nodes and collected lymph nodes, lung, liver, and spleen for histopathological examination of metastasis. During the gross examination, lymph nodes received a score of $1+, 2+$, or $3+$, depending on the size of the enlarged lymph nodes $0.1-0.5 \mathrm{~mm}, 0.5-1 \mathrm{~mm}$, and $>1 \mathrm{~mm}$, respectively; non-detectability of lymph node enlargement was scored as 0 .

In a separate study, the chemosensitization potential of Anthos was tested. Taxolresistant TNBC MDA-MB-231Tx cells $\left(5 \times 10^{6}\right.$ cells) were injected under the second inguinal nipple on the right ventral side of the mammary pad. When the tumors reached approximately $120 \mathrm{~mm}^{3}$, animals were randomized into four groups. Group 1 received vehicle control, whereas Group 2 received Anthos at $60 \mathrm{mg} / \mathrm{kg}$ by oral gavage three times a week. Group 3 received PAC at $4 \mathrm{mg} / \mathrm{kg}$ i.p. once a week, and Group 4 received a combination of Anthos and PAC at the same doses as in the individual groups. Animal health, tumor growth, and metastasis were monitored as described above.

\subsection{Statistical Analysis}

Statistical analysis was performed using the GraphPad Prism statistical software (version 4.03; La Jolla, CA, USA). Statistical significance of differences in various parameters was evaluated by unpaired Student's $t$-tests. Data in the xenograft studies are expressed as mean \pm standard error of the mean (SEM) $(n=10)$. A value of $p<0.05$ was considered statistically significant.

\section{Results}

\subsection{Anthos Inhibit the Growth of TNBC Cells by Modulating Cell-Cycle Regulatory and Survival Proteins}

We determined the anti-proliferative activity of Anthos against three TNBC cell lines-MDA-MB-231, MDA-MB-436, and HCC1937-by MTT assay. Anthos showed dose-dependent activity against all tested cell lines. The $\mathrm{IC}_{50}$ values, in ascending order, were $100 \pm 0.7,240 \pm 0.5$, and >400 $\mu \mathrm{M}$ against MDA-MB-231, MDA-MB-436, and HCC1937, respectively. This indicated that MDA-MB-231 cells were more sensitive to Anthos, with several-fold lower $\mathrm{IC}_{50}$ compared to MDA-MB-436 and HCC1937 cells (see Figure 1a). Interestingly, Anthos did not affect the growth of normal epithelial keratinocyte (HEK) cells, despite the high concentrations tested (400 $\mu \mathrm{M}$; Figure S1).

The effect of Anthos on cell-cycle progression was assessed through flow cytometry by PI staining of TNBC cells after treatment with Anthos in a dose- and time-dependent manner. Our results indicated significant G0/G1 arrest in MDA-MB-231 cells, and G2/M arrest in MDA-MB-436 and HCC1937 cells (Figures 1b and S4). These observations also occurred dose-dependently, with modulation of several key cell-cycle regulatory kinases and protein targets after Anthos treatment, including Cyclin A, Cyclin B1, Cyclin E2, p-CDC2, p-wee1, p-histone H2, and Myt1 (Figure 1c).

We next examined the induction of apoptosis by Anthos in TNBC cell lines through flow cytometry using Annexin $\mathrm{V}$ and propidium iodide (PI) staining. As shown in Figures $1 \mathrm{~d}$ and S13, a dose- and time-dependent increase in the percentage of early and late apoptotic cells after treatment with Anthos was noted. These findings confirm apoptosismediated cell killing by Anthos. Examination of cell survival- and apoptosis-related proteins indicated a dose-dependent progressive increase in the levels of cleaved caspase-3, caspase-7, and caspase-9 proteins in response to Anthos treatment. These trends were more visible in MDA-MB-231 cells, compared to MDA-MB-436 and HCC1937. An increase in cleaved PARP level with Anthos further confirmed apoptosis in these cells (Figure 1e). These results suggest that Anthos caused apoptosis by the activation of caspases in TNBCs. 
$\mathbf{a}$

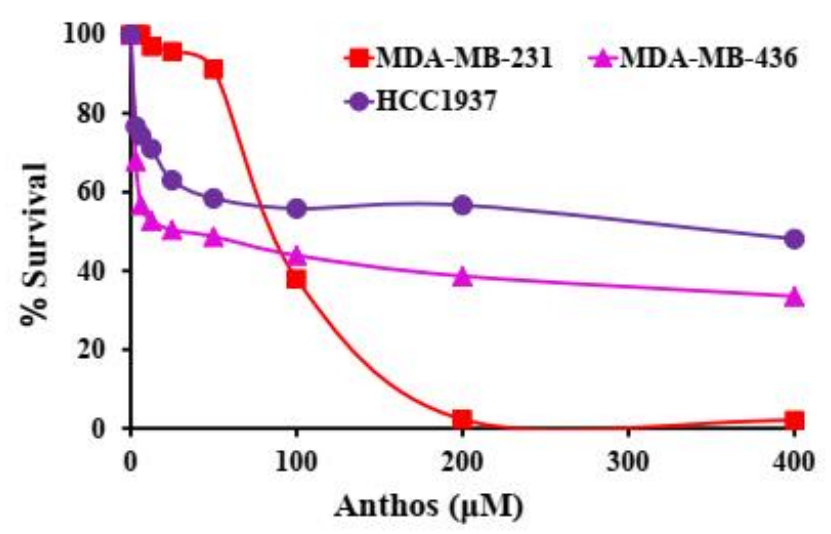

b



d

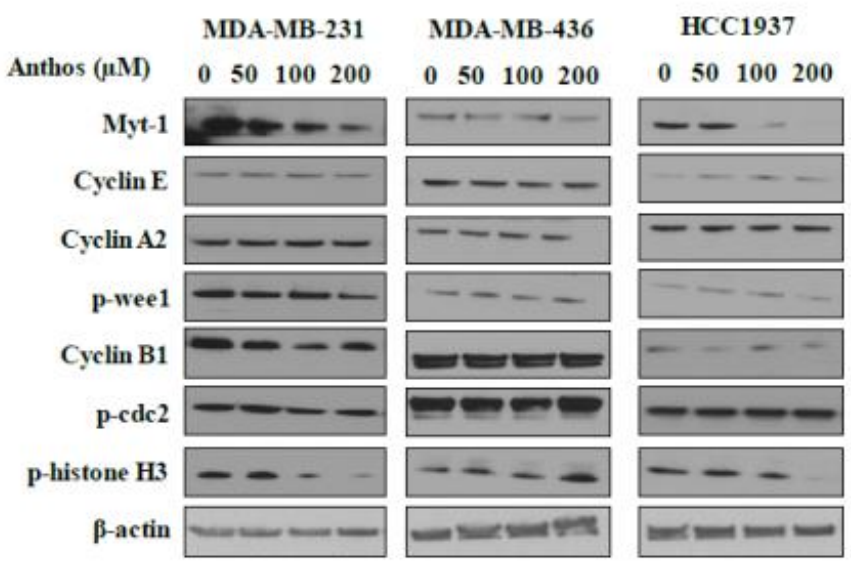

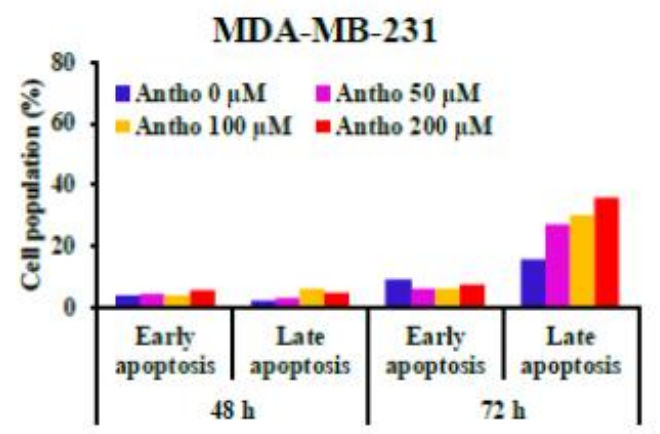

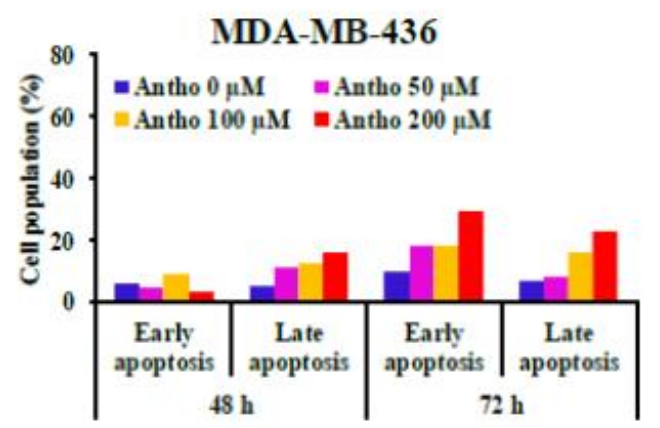

HCC1937

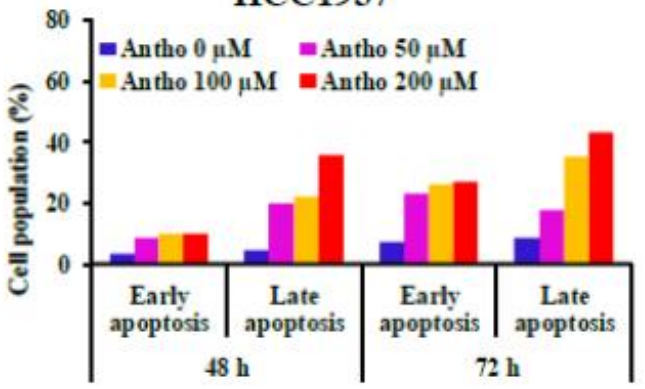

Figure 1. Effect of Anthos on cell viability, cell-cycle progression, apoptosis, and cell-cycle regulatory proteins: (a) BC cells were treated with a native mixture of Anthos $(0-400 \mu \mathrm{M})$ isolated from bilberry extract for $72 \mathrm{~h}$ and MTT assay was performed. Data denote the mean of three experiments (SD < 10\%); (b,c) MDA-MB-231, MDA-MB-436, and HCC1937 cells were treated with Anthos $(0-200 \mu \mathrm{M})$, and cell-cycle arrest (b) and apoptosis (c) were determined after staining cells with propidium iodide by flow cytometry; (d,e) BC cells were treated with Anthos $(0-200 \mu \mathrm{M})$ for $48 \mathrm{~h}$ and cell lysates were analyzed by Western blot for indicated proteins. Equal loading was confirmed by $\beta$-actin. Densitometry data are presented in Figures S2 and S3. 


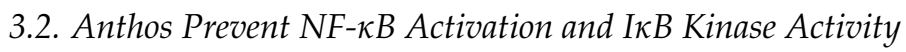

We investigated the ability of the Anthos to inhibit constitutive and TNF $\alpha$-induced NF$\mathrm{KB}$ activation and NF- $\mathrm{KB}$ binding activity by gel mobility shift assay (EMSA). In MDA-MB436 and HCC1937 cells, Anthos at $50 \mu \mathrm{M}$ diminished both constitutive and TNF $\alpha$-induced NF- $\mathrm{KB}$ activation, indicating anti-inflammatory activity. However, such inhibition in MDAMB-231 cells was much less effective (Figure 2a). Further examination of NF- $k B$ binding activity by ELISA in the presence of Anthos indicated effective inhibition of TNF $\alpha$-induced NF- $\mathrm{KB}$ binding activity in all TNBC cell lines tested. While Anthos inhibited uninduced NF- $\mathrm{kB}$ binding activity in MDA-MB-436 and HCC1937, it did not affect MDA-MB-231 cells (Figure 2b). These observations were in agreement with our EMSA assay findings.

To evaluate whether Anthos affect the nuclear translocation of NF- $k B$ through IKB phosphorylation and/or degradation, we examined the status of I $\kappa B$ phosphorylation and degradation after treatment with TNF $\alpha$ in MDA-MD-231 and MDA-MB-436 cells. We observed phosphorylation after $10 \mathrm{~min}$ of treatment, followed by its degradation with time. MDA-MB-231 cells showed rapid degradation, compared to MDA-MB-436 cells (Figure S8). Based on this finding, cells were treated with TNF $\alpha$ for 10 min for the detection of IKB phosphorylation in subsequent experiments. Our results indicated increased cytoplasmic I $\kappa B$ (Figure 2c) with a decrease in nuclear NF- $\kappa B$ levels, in a dose-dependent manner. These results suggest that Anthos antagonize the nuclear translocation of NF- $\mathrm{kB}$, inhibiting the phosphorylation of I $k B$ and its subsequent degradation. Next, we determined whether Anthos target the cellular IKK complex for NF- $\mathrm{KB}$ inhibition by monitoring the kinase activity of IKK upon treatment with Anthos. BC cells were pretreated with increasing doses of Anthos for $1 \mathrm{~h}$, followed by a $10 \mathrm{~min}$ challenge with TNF $\alpha$. Cell lysates were subjected to immunoprecipitation with an IKK $\beta$ antibody. The kinase activity of immuno-precipitated IKK complexes was determined using the ELISA method. Treatment of Anthos resulted in the neutralization of IKK complex activity in all of the TNBC cells. The effect was more pronounced in MDA-MB-436 and HCC1937 cells, compared to MDA-MB-231 cells (Figure 2d). These results confirmed that the inhibitory action of the Anthos was due to its effect on the phosphorylation and degradation of $\operatorname{IkB} \alpha$, considering the phosphorylated levels of IkB $\alpha$ protein determined by immunoblot analysis. Anthos exhibited a strong ability to inhibit IkB $\alpha$ and NF- $\mathrm{KB}$ phosphorylation in a concentration-dependent manner (Figures 2e and S13).

\subsection{Anthos Modulate EMT Markers to Inhibit Metastasis}

The effect of Anthos on the metastasis of TNBC cells in vitro was assessed through wound-healing and trans-well migration and invasion studies. Anthos at 100 and $200 \mu \mathrm{M}$ resulted in greater abrogation of metastatic potential of MDA-MB-231 and HCC1937 cells up to $48 \mathrm{~h}$ (Figure 3d), while MDA-MB-436 cell migration ability was the least affected by Anthos (Figure 3a). MDA-MB-231 and MDA-MB-436 cells were the most aggressive among the TNBC cell lines tested. Anthos treatment was less effective in inhibiting the migration ability of MDA-MB-436 cells, compared to MDA-MB-231 cells. Further, the effect of Anthos on the invasive behavior of TNBC cells was tested using Matrigel trans-well migration and invasion assay. Our results indicated that Anthos could effectively inhibit both native (Figure 3b) and TGF $\beta$-induced invasiveness of MDA-MB-231 and HCC1973 (Figure 3b). 
a

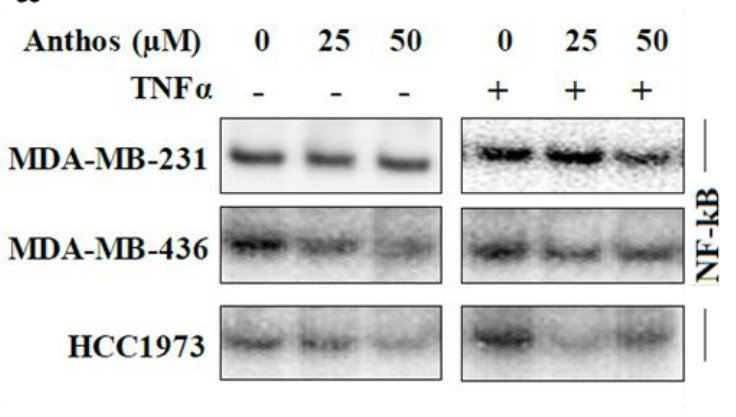

b

Anthos $(\mu \mathrm{M}) \quad 0 \quad 0 \quad 50100200 \quad 0 \quad 0 \quad 50100200$

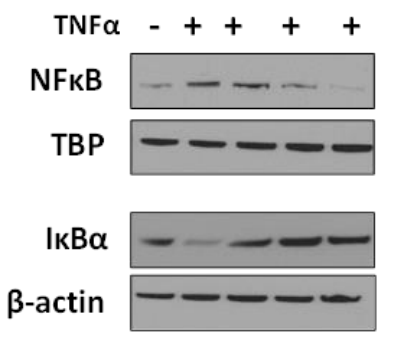

MDA-MB-436

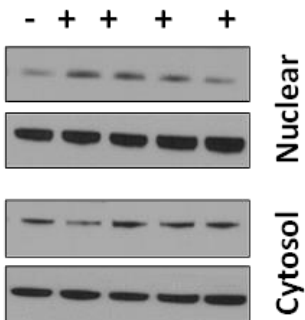

c

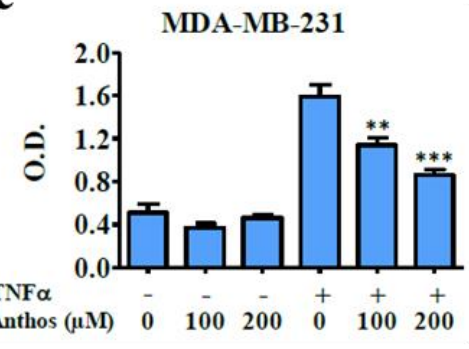

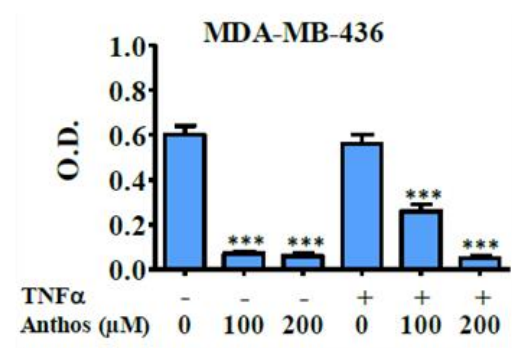

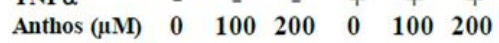

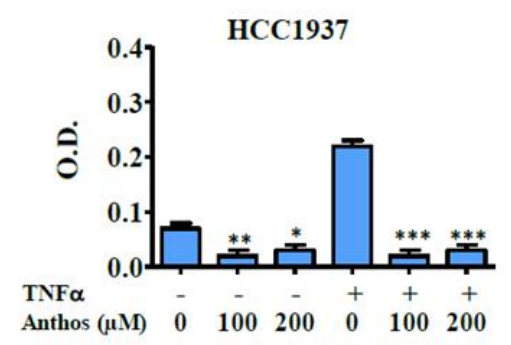

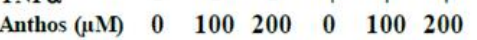
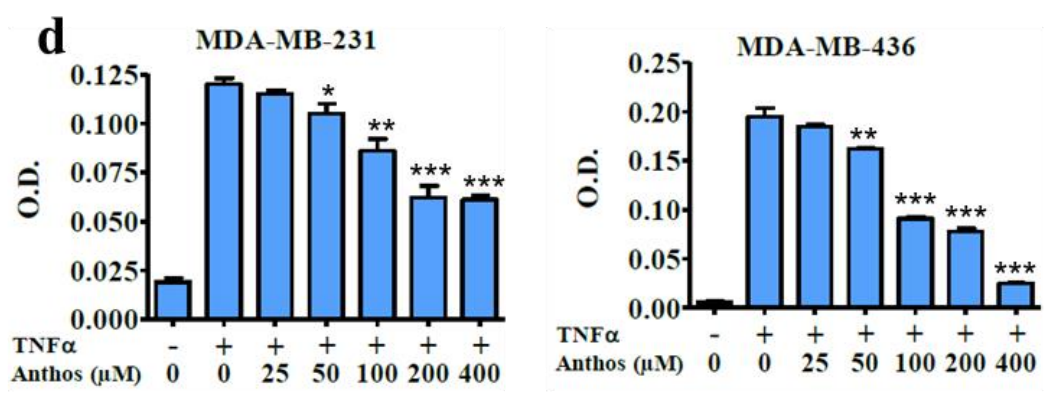

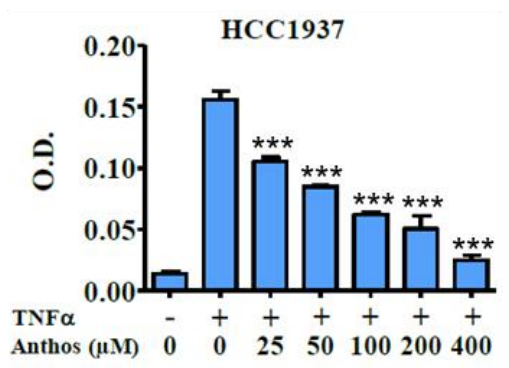

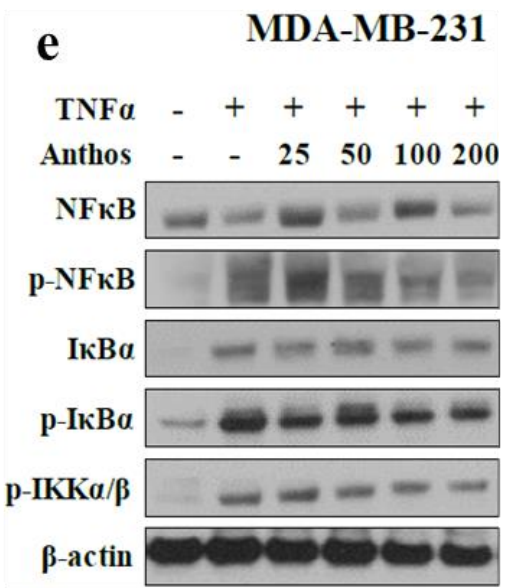
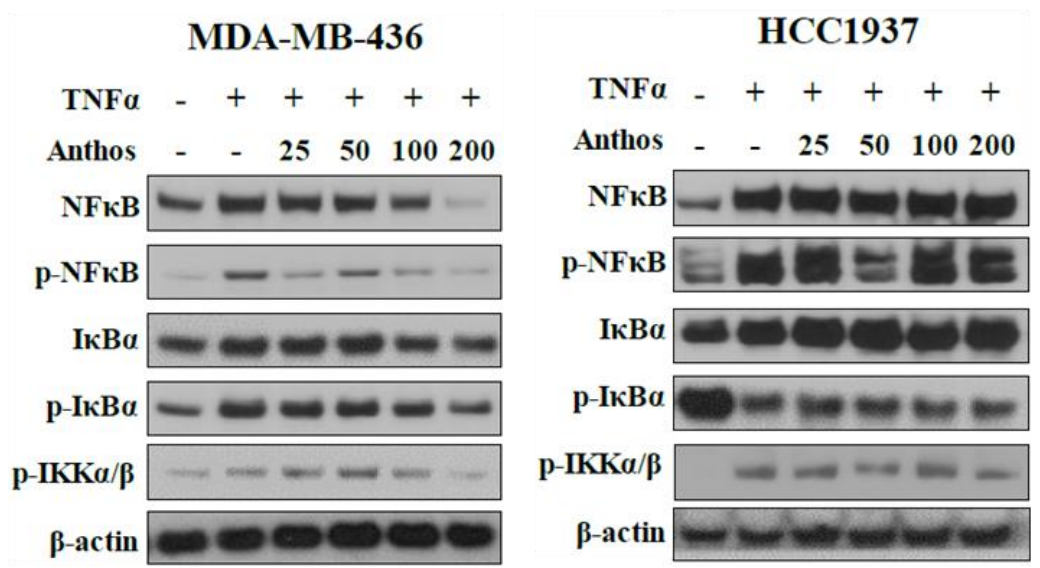

Figure 2. Effect of Anthos on NF- $\mathrm{kB}$ activation, nuclear translocation, and related protein molecules in TNBC: (a) BC cells were treated with Anthos $(0-50 \mu \mathrm{M})$ in the presence or absence of TNF $\alpha$ for $48 \mathrm{~h}$ and nuclear extracts were analyzed by EMSA; (b) Cells were treated with Anthos $(0-200 \mu \mathrm{M})$ for $48 \mathrm{~h}$, and nuclear and cytosol lysates were probed for NF- $\mathrm{kB}$ and $\mathrm{I} \kappa \mathrm{B} \alpha$ proteins by Western blot. Equal loading was confirmed by tata binding protein (TBP) and $\beta$-actin, respectively; (c) Effect of bilberry Anthos on NF- $\mathrm{BB}$ activation. Breast cancer cells were treated with Anthos (100 and $200 \mu \mathrm{M})$ in presence or absence of TNF $\alpha$ for $48 \mathrm{~h}$, and nuclear extracts were analyzed by ELISA: (d) Whole-cell lysates were prepared and immune-precipitated with anti-IKK $\beta$ antibody. The immuno-complex kinase assay was performed by ELISA using a CycLex ${ }^{\circledR}$ IKK $\alpha$ and $\beta$ Kinase Assay /Inhibitor Screening Kit; (e) Whole-cell lysates were probed for I BB $\alpha$ and P65 levels. Equal loading confirmed by $\beta$-actin. Statistical analysis was carried out using student's $t$-test; ${ }^{*} p<0.05 ;{ }^{* *} p<0.01$; *** $p<0.001$. Densitometry data are presented in Figures S5-S7. 
a

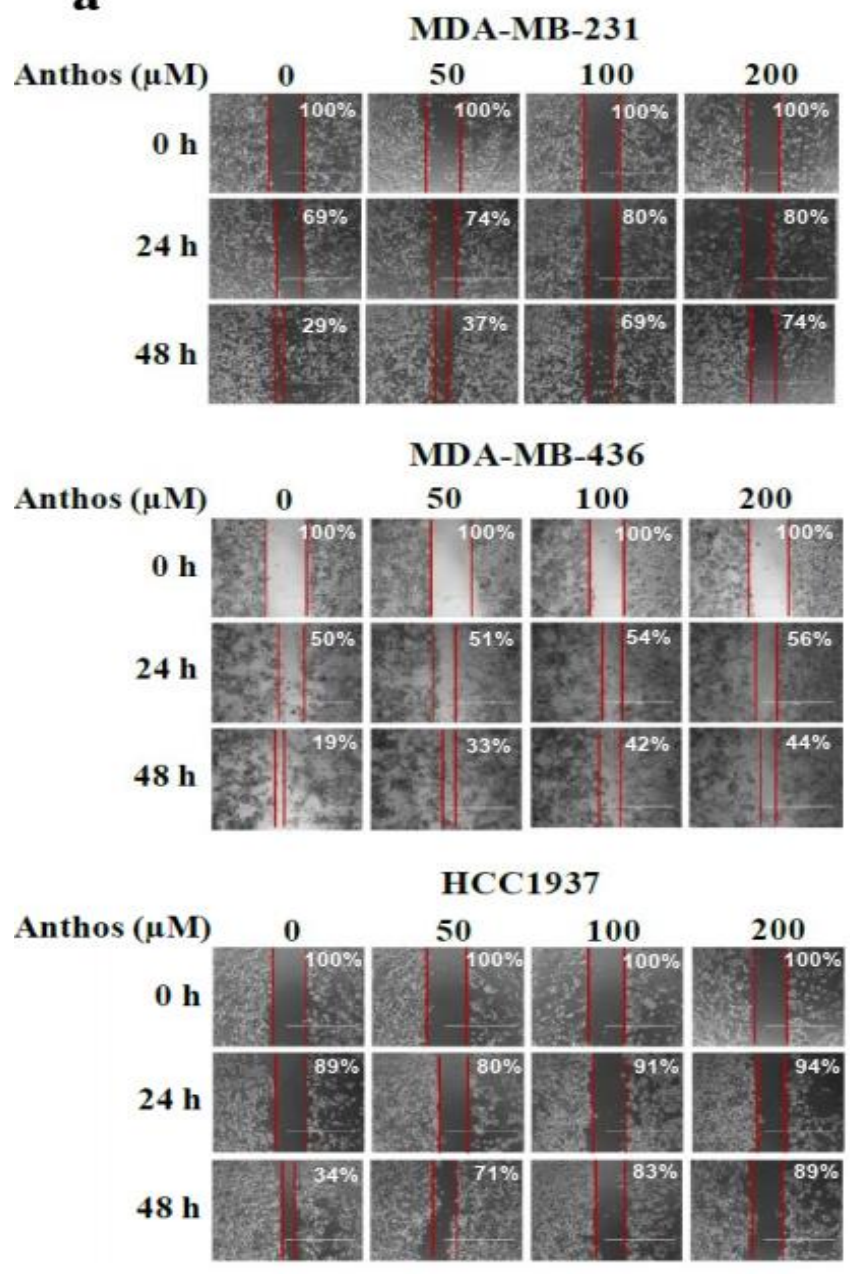

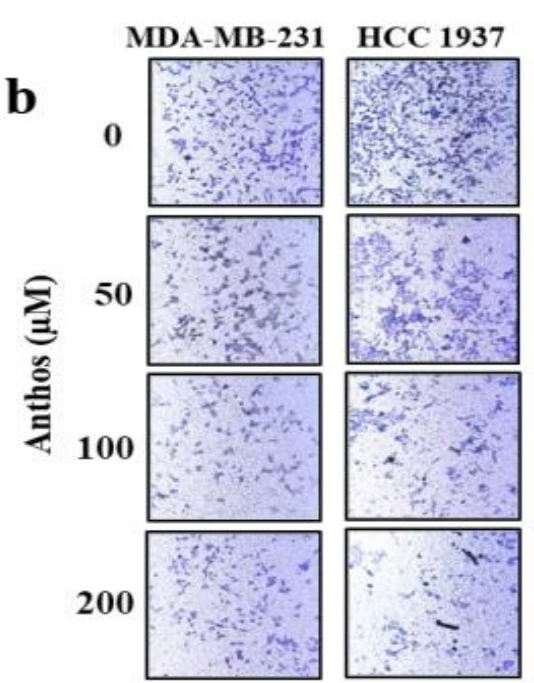

c

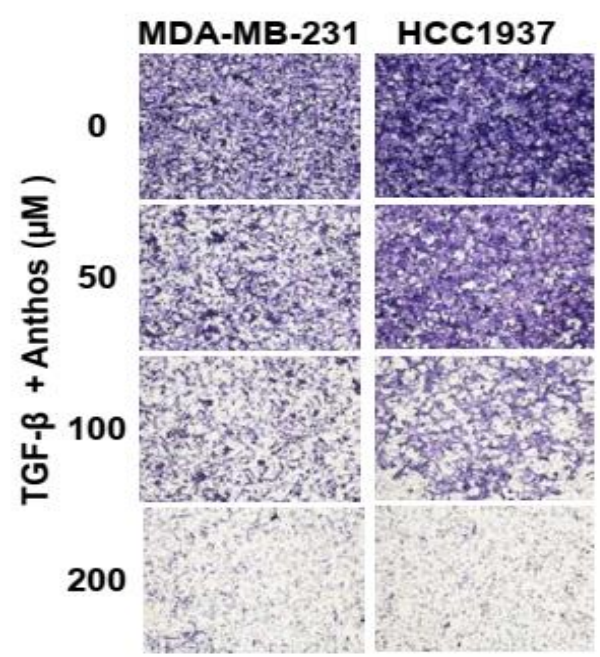

d

MDA-MB-231 MDA-MB-436

HCC1937

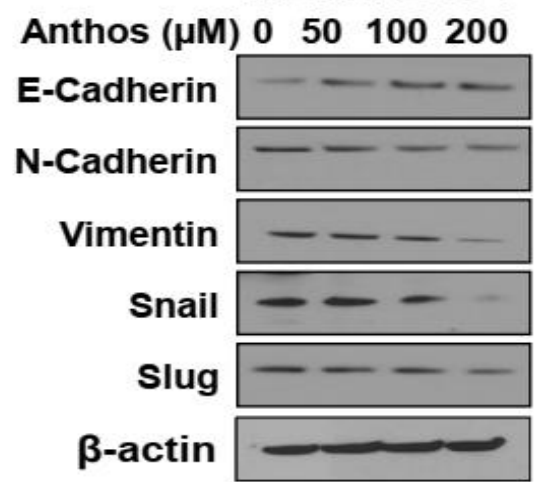

050100200
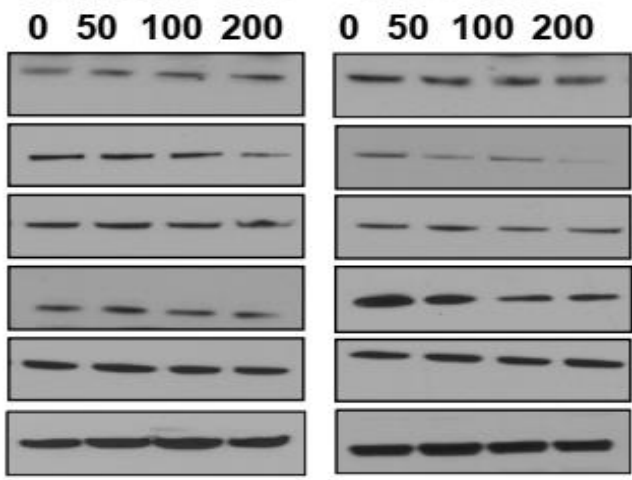

Figure 3. Effect of Anthos on cell migration, invasion, and EMT pathway proteins: (a) BC cells seeded in 2-Well CultureInsert in a 24-well plate (Ibidi ${ }^{\circledR}$, Munich, Germany), resulting in a $1 \mathrm{~mm}$ wide wound. The inserts were removed after overnight incubation and cells were treated with Anthos $(0-200 \mu \mathrm{M})$. Migration was assessed after $24 \mathrm{~h}$ and $48 \mathrm{~h}$ of Anthos treatment, represented as the percentage reduction in wound area; $(\mathbf{b}, \mathbf{c})$ Cells seeded in matrigel-coated transwell inserts. The bottom chamber was treated with Anthos $(0-200 \mu \mathrm{M})$ in the absence $(\mathbf{b})$ and presence (c) of TGF $\beta$. Invasive cells at the bottom of the trans-well insert were visualized after staining with $0.2 \%$ toluidine blue; (d) Cells were treated with Anthos $(0-200 \mu \mathrm{M})$ for $48 \mathrm{~h}$ and whole-cell lysates were probed for EMT pathway proteins. Equal loading confirmed by $\beta$-actin. Densitometry data from panel D are presented in Figure S9. 
Next, we investigated the effects of the Anthos on EMT markers, in order to validate the reduced migration and invasion abilities observed above. Our findings indicated that Anthos induced E-cadherin and inhibited N-cadherin, Vimentin, Snail, and Slug expression and, consequently, the metastatic phenotype TNBC cells. These findings demonstrate, for the first time, the role of Anthos in the regulation of EMT through the induction of E-cadherin and inhibition of Snail (Figure 3c).

\subsection{Anthos Inhibited Growth and Metastasis of Orthoxenograft Tumors}

Before examining the effect of the Anthos on orthotopic TNBC xenografts in a mouse model, we first launched a pilot study to establish the growth rate of TNBC xenografts in our laboratory. The three TNBC cell lines were tested for six weeks, in order to establish tumor growth rates and metastatic ability in two mouse models; namely, athymic nude and NOD-Scid mice. HCC1937 and MDA-MB-231 cells exhibited linear growth rates in the NOD-Scid mice, while MDA-MB-436 cells showed linear growth of orthotopic tumors in athymic nude mice. Although MDA-MB-231and HCC1937 xenografts were well-established in nude mice, the variability among tumor size was larger, compared to those established in NOD-Scid mice. MDA-MB-436 cells exhibited larger variability in the NOD-Scid mouse model (Figure S10). To determine if the orthotopic tumor xenografts resulted in distant metastasis, we conducted a gross examination of lymph nodes at the end of the study. Our findings indicated enlargement of lymph nodes with the highly metastatic MDA-MB-231 and MDA-MB-436, while HCC1937 cells showed weak metastasis in NOD-Scid mice. None of the cell lines resulted in metastasis in athymic nude mice.

Given the above findings, we chose to use MDA-MB-231 to test Anthos, as it exhibited less variability in tumor size and more linear growth and metastasis, compared to the other cell lines, in the NOD-Scid mouse model. In this study, $2.5 \times 10^{6} \mathrm{MDA}-\mathrm{MB}-231$ cells were injected under the second inguinal nipple on the right ventral side of the mammary pad. When the tumor volume reached approximately $120 \mathrm{~mm}^{3}$, the animals were randomized into three groups. Group 1 received vehicle control, whereas Groups 2 and 3 received Anthos at $30 \mathrm{mg} / \mathrm{kg}$ and $60 \mathrm{mg} / \mathrm{kg}$, respectively, by oral gavage three times a week. After 6 weeks of intervention, both doses of Anthos resulted in a significant decrease in tumor volume, compared to control. However, the anti-tumor effect at the higher dose was more pronounced (Figure $4 \mathrm{a}$ ). At euthanasia, we examined for gross metastasis in lymph nodes and collected lymph nodes, lung, liver, and spleen for histopathological examination of metastasis. During the gross examination, lymph nodes received a score of $1+, 2+$, and $3+$, depending on the size of the enlarged lymph nodes: $0.1-0.5 \mathrm{~mm}$, $0.5-1 \mathrm{~mm}$, and $>1 \mathrm{~mm}$, respectively; absence of lymph node enlargement was scored as 0 . Results of the observation of thoracic and inguinal lymph nodes are shown in Figure $4 \mathrm{~b}$ and Table S1. Our findings suggest that macro-metastasis of lymph nodes was significantly decreased by Anthos intervention at both doses, compared with the vehicle control group. The higher dose of Anthos $(60 \mathrm{mg} / \mathrm{kg})$ led to smaller tumor size and a lower total number of enlarged lymph nodes, compared to both the lower dose and the control group. Histopathological examination confirmed lymph node and lung metastasis of MDA-MB-231 cells. No metastasis for the liver or spleen was observed in any of the groups. High-dose Anthos exhibited a lower rate of lymph nodes and lung metastasis, compared to the lower dose Anthos.

\subsection{Anthos Chemosensitize PAC-Resistant Cells by Modulating Drug Transporters}

After establishing the anti-cancer effects of Anthos against MDA-MB-231 cells and tumors, we sought to investigate whether Anthos had an inhibitory effect on PAC-resistant MDA-MB-231 (MDA-MB-231Tx) cells. The effect of the Anthos alone and in combination with PAC on the cell growth inhibition of parental MDA-MB-231 and PAC-resistant MDAMB-231Tx cells was determined by MTT assay. Our findings indicated significant inhibition of cell proliferation of MDA-MB-231Tx cells (Figure 5a), and that the $\mathrm{IC}_{50}$ values of Anthos and PAC alone were $160 \mu \mathrm{M}$ and $597 \mathrm{nM}$, respectively; however, the $\mathrm{IC}_{50}$ value of PAC was 
substantially reduced ( $29 \mathrm{nM})$ when PAC was combined with Anthos. Thus, Anthos-PAC combined treatment resulted in a near 20-fold lowering of the $\mathrm{IC}_{50}$ of PAC (Figure 5a).

$\mathbf{a}$

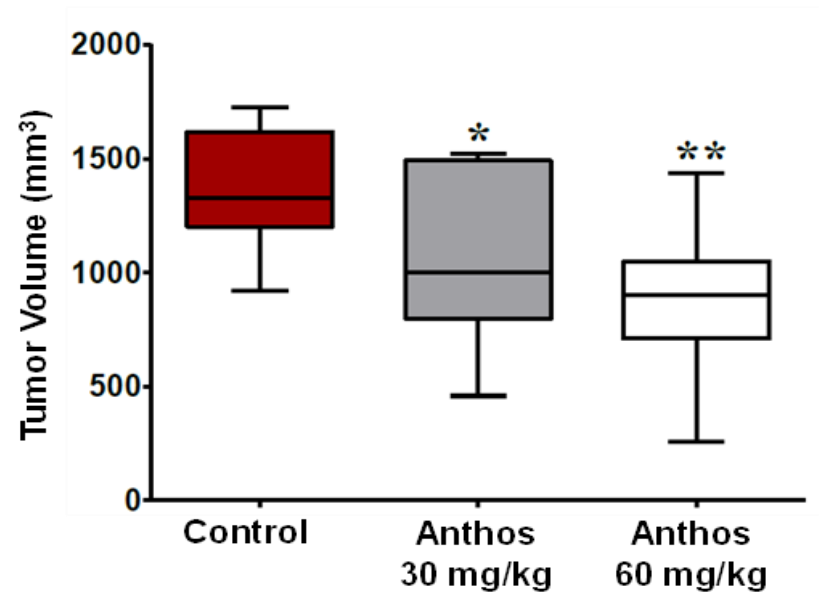

b

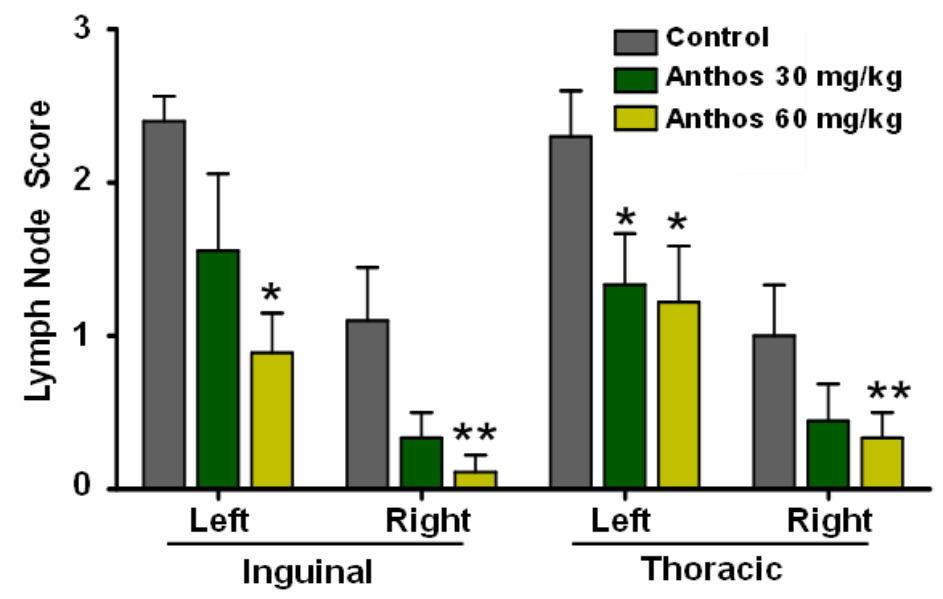

Figure 4. Effect of Anthos on tumor growth inhibition and lymph node metastasis: (a) NOD-Scid mice were inoculated (Ventral right, under second inguinal nipple) with MDA-MB-231 BC cells ( $2.5 \times 10^{6}$ cells) to produce an orthotopic tumor. When the tumor grew to $120 \mathrm{~mm}^{3}$, animals were treated (oral gavage, three times a week) with Anthos (30 mg/kg or $60 \mathrm{mg} / \mathrm{kg}$ b.wt.). Control groups received PBS; (b) At euthanasia, lymph nodes were scored for size (as 0, 1+, 2+, or 3+). Data represent average \pm SE $(n=9-10)$. Data represent average \pm SE $(n=9-10)$. Statistical analysis was carried out using student's $t$-test; ${ }^{*} p<0.05 ;{ }^{* *} p<0.005$.

As it is well-known that drug transporters play a crucial role in cancer drug resistance [27], we examined the expression levels of several drug transporters, including ABCB1 (MDR1), ABCC1 (MRP1), ABCG2/BCRP, and LRP/MVP, in MDA-MB-231Tx cells by RT-PCR. Our findings indicated over 3.2- to 5.5-fold increased expression of these drug transporters, compared to parental MDA-MB-231 cells (Figure 5b). Later, we examined whether the chemosensitizing effects of Anthos were mediated by the modulation of drug-transporter proteins. To this end, MDA-MB-231Tx cells were treated with Anthos, PAC, and PAC + Anthos (Figure 5d). While treatment of MDA-MB-231Tx cells with PAC resulted in a further increase in the expression of all of the resistance-conferring drug transporter proteins, treatment with Anthos exhibited dose-dependent down-regulation of these makers. Furthermore, combination treatment with PAC + Anthos showed the reversal of resistance marker expression levels (Figure 5c).

\subsection{Anthos Inhibits PAC-Induced NF- $\kappa B$ to Overcome Drug Resistance}

$\mathrm{NF}-\mathrm{kB}$ is well-known to be constitutively activated in many types of cancer, including TNBC cells [28]. Moreover, PAC is known to induce NF- $\kappa B$ activation [29]. We investigated the ability of Anthos, alone and in combination with PAC, to inhibit NF- $k B$ activation in MDA-MB-231Tx cells. Our findings suggest that combination treatment inhibited PACinduced NF- $\kappa$ B activity, while Anthos alone did not affect it (Figure 6a). Further, NF- $\kappa B$ binding activity in presence of Anthos indicated effective inhibition of TNF $\alpha$-induced NF- $\kappa B$ binding activity in MDA-MB-231Tx, compared to constitutive levels (Figure 6b). We also examined the status of IKB phosphorylation and degradation after treatment with TNF $\alpha$ in MDA-MB-231Tx. We observed that similar to MDA-MB-231 cells, MDA-MB231Tx cells exhibited I $\kappa \mathrm{B} \alpha$ phosphorylation after $10 \mathrm{~min}$ of TNF $\alpha$ treatment, followed by its degradation with time (Figure S11). Pre-treatment with Anthos followed by a $10 \mathrm{~min}$ challenge with TNF $\alpha$ resulted in the neutralization of IKK complex activity in MDA-MB231Tx cells (Figure 6c). 
$\mathbf{a}$

\begin{tabular}{|l|c|c|c|c|c|}
\hline \multirow{2}{*}{ Cell Lines } & \multicolumn{5}{|c|}{ Median Inhibitory Concentration (IC50)s } \\
\cline { 2 - 6 } & $\begin{array}{c}\text { PAC } \\
(\mathbf{n M})\end{array}$ & $\begin{array}{c}\text { ANTHOS } \\
\text { (uM) }\end{array}$ & $\begin{array}{c}\text { PAC+ANTHOS } \\
\text { (nM) }\end{array}$ & $\begin{array}{c}\text { Combination } \\
\text { Index (CI) }\end{array}$ & $\begin{array}{c}\text { Fold Reduction in } \\
\text { PAC IC50 Conc }\end{array}$ \\
\hline MDA-MB-231 & 146 & 103 & 24 & 0.73 & 6 \\
\hline MDA-MB-231Tx & 597 & 160 & 29 & 0.5 & 20.5 \\
\hline
\end{tabular}

b

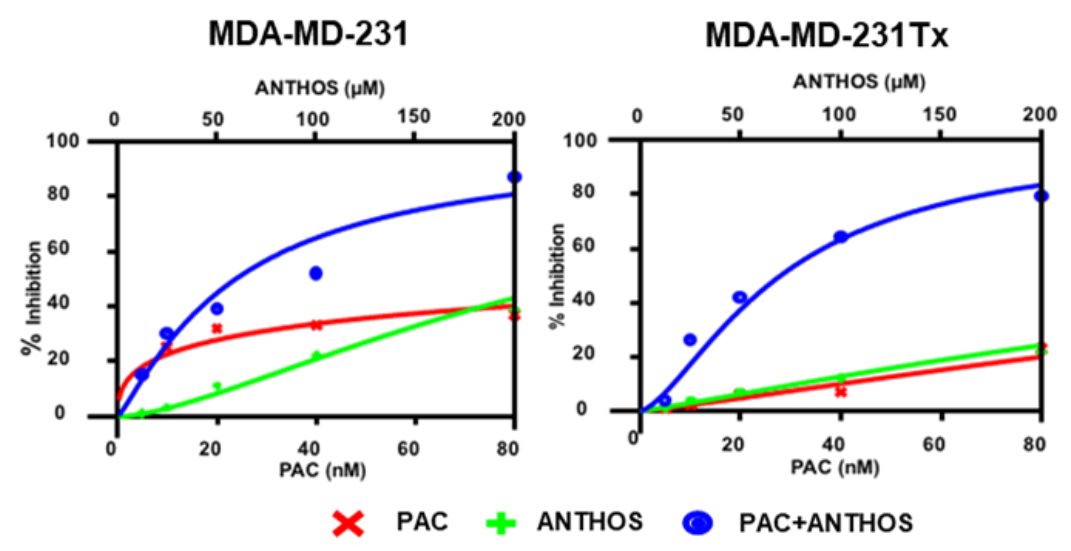

c

d

MRP1
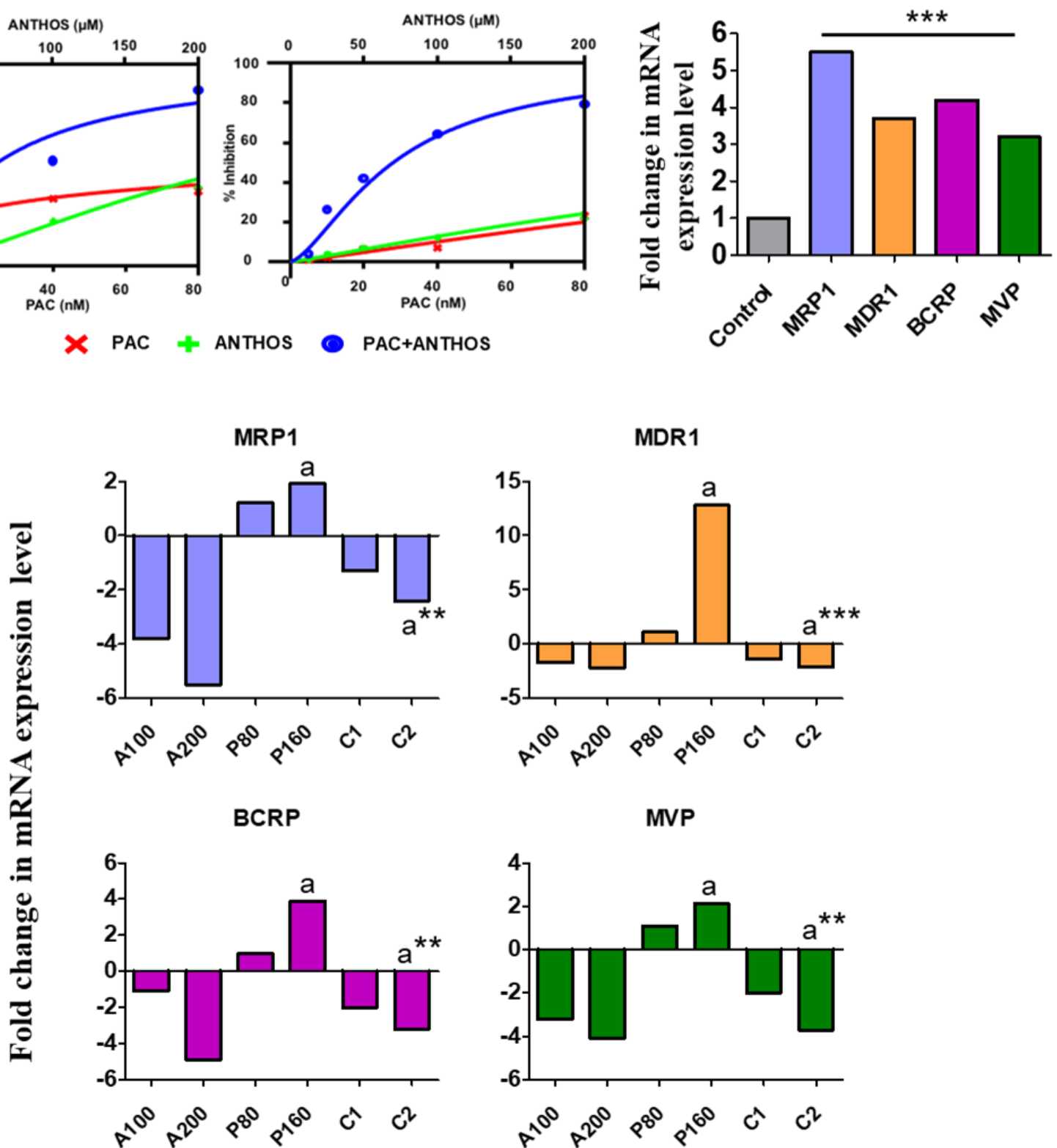

MVP

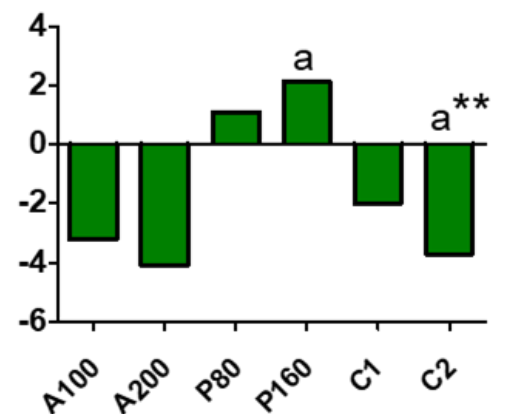

Figure 5. Anti-proliferative and synergistic activity of Anthos against parental and paclitaxel (PAC)-resistant BC cells and effects on resistant gene markers: (a,b) Drug-sensitive (MDA-MB-231) and drug-resistant (MDA-MB-231Tx) cells were treated with Anthos and PAC, alone and in combination, at various concentrations. Anti-proliferative activity was determined by MTT assay. $\mathrm{IC}_{50}$ values, of individual and combination treatments, and combination index were calculated using the Calcusyn software; (c) Expression levels of resistant gene markers (MRP1, MDR1, BRCP, and MVP) were determined using RT-PCR. The bar graph depicts the fold increase in mRNA expression of resistance proteins in MDA-MB-231Tx cells compared to parental MDA-MB- 231 cells; (d) MDA-MB-231Tx were treated with indicated doses of 
Anthos $(\mathrm{A} ; \mu \mathrm{M})$ and PAC $(\mathrm{P} ; \mathrm{nM}) . \mathrm{C} 1$ and $\mathrm{C} 2$ indicate combination treatment with PAC:Anthos at 1:1250; $\mathrm{C} 1=\mathrm{PAC} 80 \mathrm{nM}+$ Anthos $100 \mu \mathrm{M}$ while $\mathrm{C} 2=$ PAC $160 \mathrm{nM}+$ Anthos $200 \mu \mathrm{M}$. Significant differences between groups are indicated by a and $\mathrm{a}^{* *}{ }^{* *} p<0.01,{ }^{* * *} p<0.001$.

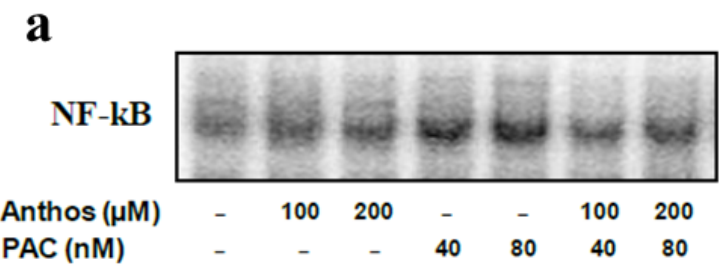

b

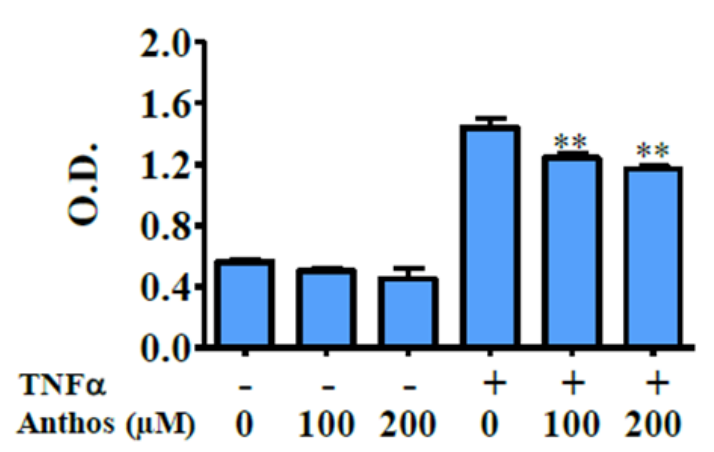

c

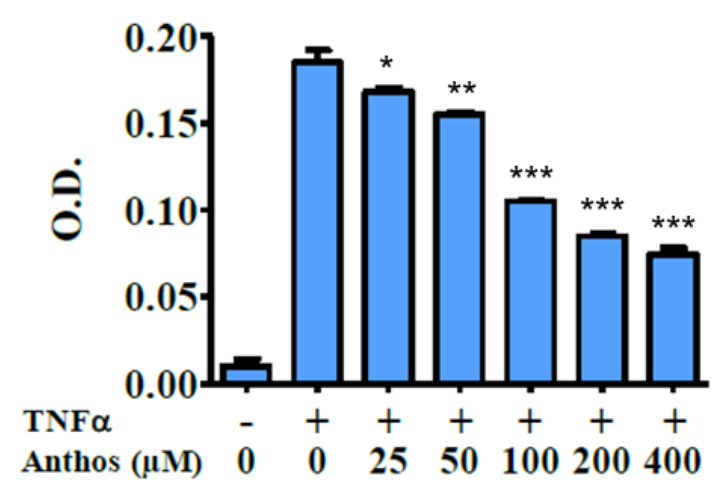

d

TNFa -++++

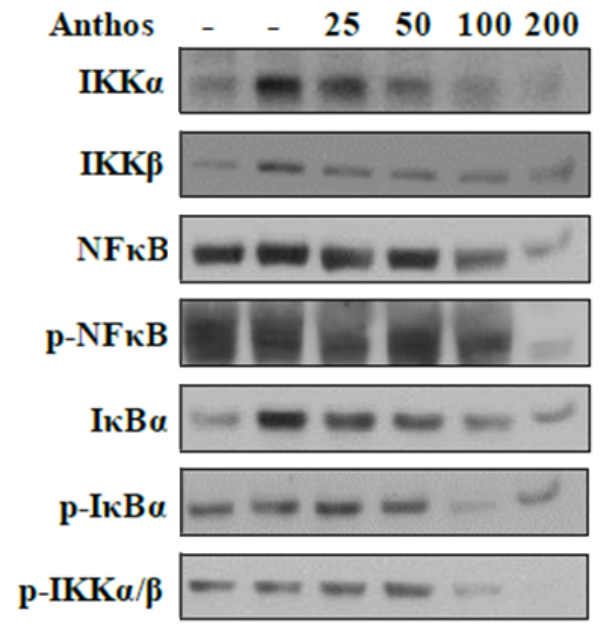

e

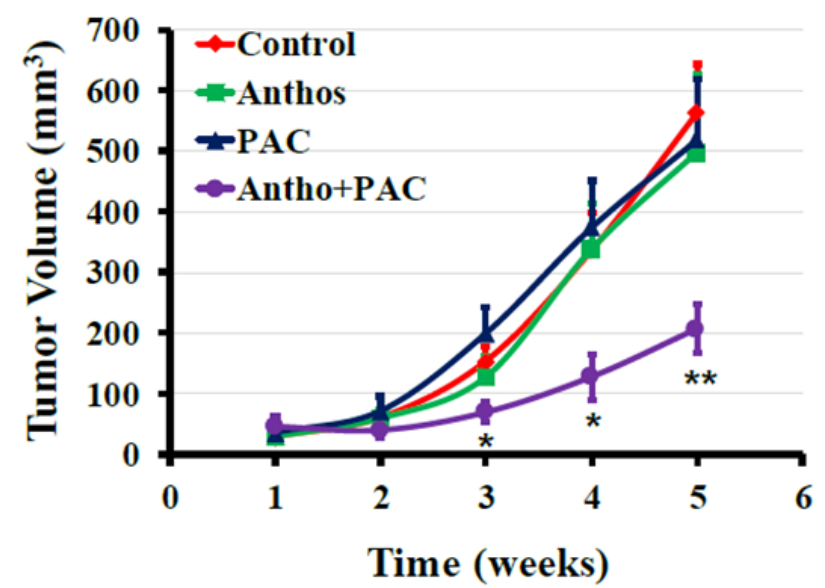

Figure 6. Effect of Anthos on NF- $\mathrm{B}$ B activation, NF- $\mathrm{kB}$ pathway proteins, and tumor growth inhibition of PAC-resistant $\mathrm{BC}$ cells: (a) MDA-MB-231Tx cells were treated with Anthos and PAC, alone and in combination, for $48 \mathrm{~h}$ and nuclear extracts were analyzed by EMSA; (b) BC cells were treated with Anthos (100 and $200 \mu \mathrm{M})$ in presence or absence of TNF- $\alpha$ for $48 \mathrm{~h}$ and nuclear extracts were analyzed by ELISA; (c) Whole-cell lysates were prepared and immune-precipitated with anti-IKK $\beta$ antibody. The immuno-complex kinase assay was performed by ELISA using CycLex ${ }^{\circledR}$ IKK $\alpha$ and $\beta$ Kinase Assay/Inhibitor Screening Kit; (d) BC cells were treated with Anthos (0-200 $\mu \mathrm{M})$ for $48 \mathrm{~h}$. Whole-cell lysates were probed for $\mathrm{I} \kappa \mathrm{B} \alpha$ and $\mathrm{P} 65$ levels. Equal loading confirmed by $\beta$-actin; (e) Effect of Anthos on MDA-MB-231Tx tumor growth inhibition. NOD-Scid mice were inoculated with MDA-MB-231Tx BC cells $\left(2.5 \times 10^{6}\right.$ cells $)$ under the nipple to produce orthotopic tumors. When tumor xenografts grew to $\sim 120 \mathrm{~mm}^{3}$, animals were treated with Anthos $(60 \mathrm{mg} / \mathrm{kg} \mathrm{b}$. wt.; 3 times/week; oral gavage), PAC (4 mg/kg, b. wt; once weekly; i.p.), or both. Control groups were treated with PBS. Data represent average $\pm \operatorname{SE}(n=10)$. Statistical analysis was c using student's $t$-test; ${ }^{*} p<0.05 ;{ }^{* *} p<0.01,{ }^{* * *} p<0.001$. Densitometry data from panels A and D are presented in Figure S12. 
Next, we evaluated the effect of Anthos on IKK $\alpha$, IKK $\beta$, NF-kB, p-NF-kB, IkB $\alpha$, $\mathrm{p}$-IkB $\alpha$, and $\mathrm{p}-\mathrm{IKK} \alpha / \beta$ in MDA-MB-231Tx cells. Anthos decreased the TNF $\alpha$-induced levels of pNF-kB and p-IkB $\alpha$ (Figure $6 \mathrm{~d}$ ). As phosphorylation of IkB $\alpha$ is mediated by IKKs [30], we also examined whether stimulation of IkB $\alpha$ by Anthos was mediated by IKK $\alpha$ and IKK $\beta$. Figure $6 \mathrm{~d}$ shows that Anthos treatment, indeed, decreased the protein levels of IKK $\alpha$, IKK $\beta$, and $p-I K K \alpha / \beta$, indicating the ability of Anthos to facilitate apoptosis by impeding the NF- $\mathrm{kB}$ survival pathway as a consequence of $\mathrm{IkB} \alpha$ stimulation.

Finally, we tested the effect of Anthos and PAC, alone and in combination, on the growth and metastasis of MDA-MB-231Tx orthoxenografts in NOD-Scid mice. In this study, $5 \times 10^{6}$ MDA-MB-231Tx cells were injected under the second inguinal nipple on the right ventral side of the mammary pad. When the tumors reached approximately $120 \mathrm{~mm}^{3}$ in volume, the animals were randomized into four groups. Group 1 received vehicle control, whereas Group 2 received the Anthos at $60 \mathrm{mg} / \mathrm{kg}$ by oral gavage three times a week, Group 3 received PAC at $4 \mathrm{mg} / \mathrm{kg}$ (i.p.) once a week, and Group 4 received a combination of Anthos and PAC at the same respective doses as used individually. After 5 weeks of intervention, both Anthos and PAC alone were found to be ineffective in decreasing tumor volume. However, the combination group resulted in a significant decrease in tumor volume, compared to the control, as early as 3 weeks (Figure 6e). The gross examination revealed the absence of lymph nodes or distant metastasis. Histopathological examination confirmed the absence of metastasis in any of the groups.

\section{Discussion}

BC treatment has been significantly improved due to advancements in surgery, radiotherapy, and adjuvant chemotherapy. Further, with the development of targeted therapies, the outcomes for patients diagnosed with hormone receptor-positive (HR+) and/or human epidermal growth factor receptor 2-positive (HER2+) BC has continued to improve. However, the same cannot be said for those affected with TNBC [31]. TNBC is extremely aggressive, more likely to metastasize than other subtypes of $\mathrm{BC}$, and has a poor prognosis, compared with hormone-responsive sub-types [5]. In this study, we demonstrated that Anthos inhibited the growth of human TNBC cells, both in vitro and in vivo, by modulating cell-cycle regulatory and survival proteins, as well as by preventing NF- $\mathrm{KB}$ activation and I $\kappa B$ kinase activity. A direct effect of Anthos, in modulating EMT markers to inhibit metastasis and in chemosensitizing PAC-resistant cells by modulating drug transporters, was further demonstrated. We also showed, for the first time, that Anthos inhibits PAC-induced NF- $\mathrm{kB}$ to overcome drug resistance.

We, and others, have previously demonstrated the strong anti-oxidant activities of anthocyanins and Anthos [32,33]. Anthos scavenge free radicals and, thus, reduce damage to the genome of normal cells by oxidative stress and the subsequent malignant transformation by gene mutation, thereby preventing the occurrence of tumors [34]. In this study, we showed the strong anti-proliferative activity of Anthos against various TNBC cells, with the highest activity against MDA-MB-231. Anti-proliferative and anti-cancer activities have been previously shown, by both our group and others, against lung, breast, and ovarian cancer cells $[6,22,33]$. We have also demonstrated the higher activity of bilberry Anthos when used as a native mixture rather than individual entities [6]. MDA-MB-231 BC cells were more sensitive to Anthos, compared to other cell lines. The effect of Anthos on MDA-MB-231 was associated with G0/G1 arrest, while G2/M arrest was observed in MDAMB-436 and HCC1937 cells. In agreement with other studies [35,36], we demonstrated that Anthos inhibited cell growth and cell-cycle progression in a dose-dependent manner. Cell-cycle arrest was also associated with the modulation of key protein targets, such as Cyclin A, Cyclin B1, Cyclin E2, p-CDC2, p-wee1, and p-histone H2. Cyclin B1 is involved in neoplastic transformation and, thus, promotes the proliferation of tumor cells. Therefore, its down-regulation — consequently reducing the activity of Cdk1/Cyclin B1—could block the aggressive proliferation of tumor cells [37]. 
A direct link between apoptosis and the cell cycle is supported by the fact that mitosis and apoptosis display very similar morphological features [38]. We noted that Anthos exhibits cell growth inhibition through the induction of apoptosis, resulting from the activation of Poly(ADP-ribose) polymerase (PARP) protein cleavage. These results are in agreement with other studies, in which Anthos and one of its constituents-delphinidinhas also been shown to cause apoptosis and PARP cleavage [35,36,39,40]. PARP activation takes place in response to DNA fragmentation during the induction of apoptosis and is, therefore, considered an important biomarker. It has been also reported that Anthos could induce apoptosis through the internal mitochondrial and external death receptor pathway [41].

NF- $\mathrm{KB}$ is known to be constitutively activated in several TNBC cells, including MDAMB-231. NF- $\mathrm{KB}$ overexpression has been implied in aggressive tumor biology in BC, leading to poor prognosis; therefore, NF- $\mathrm{KB}$ positive tumors need to be treated aggressively. NF- $\kappa B$ activation has been correlated with high-grade, large tumor size, ER negativity, PR negativity, and HER-2/neu positivity in BC patients [42]. Anthos has been shown to act as NF-kB inhibitors by preventing the activation of IkB kinase B (IKK $\beta$ ), IkB phosphorylation and degradation, and NF-kB/DNA binding and gene transcription [39]. We investigated the ability of Anthos to inhibit constitutive levels and TNF $\alpha$-induced NF- $\mathrm{kB}$ activation by measuring NF- $\mathrm{KB}$ binding activity. Our results indicated a dose-dependent inhibition of $\mathrm{TNF} \alpha$-induced NF- $\mathrm{KB}$ binding activity in MDA-MB-231 and MDA-MB-436 cells, additionally confirming that Anthos exerted its effect through the phosphorylation and degradation of $\operatorname{IkB} \alpha$.

In tumors, NF- $\mathrm{kB}$ signaling is activated by $\mathrm{TNF} \alpha$, which stimulates cell survival, proliferation, epithelial-mesenchymal transition (EMT), migration, and chemo-resistance [43,44]. EMT in BC requires NF- $\mathrm{KB}$ activity [45], which induces and maintains EMT in model systems through two mechanisms: Up-regulation of EMT master-switch transcription factors and stabilization of Snail [46]. In the first mechanism of EMT, epithelial cells lose the epithelial markers E-cadherin and cytokeratin and acquire mesenchymal markers, including N-cadherin, fibronectin, vimentin, and some soluble metalloproteinases [47]. Our data showed that Anthos induced E-cadherin and inhibited N-cadherin, vimentin, snail, and slug expression, indicating the ability of Anthos to regulate EMT signaling through induction of E-cadherin and inhibition of Snail. Individual anthocyanidins (delphinidin, cyanidin, pelargonidin, petunidin, and malvidin) have been shown to alter the expression of snail [47]. Similar findings, in which anthocyanins modulated genes involved in EMT processes by inhibiting NF- $\mathrm{kB}$, have been reported [48,49].

To determine the effect of Anthos on tumor growth and lymph node metastasis, MDAMB-231 orthoxenografts were established in a NOD-Scid mouse model. The orthotopic xenograft models represent a clinically relevant model, with respect to the tumor's primary site, micro-environment, and metastasis. Anthos significantly decreased tumor volume, compared to control; however, as expected, the effect was more pronounced at the higher dose $(60 \mathrm{mg} / \mathrm{kg})$. After anti-tumor efficacy, we examined the effect on metastasis and found that macro-metastasis of lymph nodes was significantly decreased by the Anthos intervention, compared with vehicle treatment. EMT is often activated during cancer invasion and metastasis. As Anthos inhibit molecules involved in EMT and downregulate various cyclins, including Cyclin B1, these could comprise a possible mechanism for Anthos to inhibit cancer metastasis. Our group, and others, have demonstrated the anti-cancer activity of Anthos in animal models [18-20,50]; however, this is probably the first report of Anthos against orthotopic BC.

Chemotherapeutic drugs, such as PAC, alone or in combination with anthracycline agents, are the first-line chemo drugs used for MBC treatment [51,52]. Resistance to chemotherapy, developed following the exposure of tumor cells to a chemotherapeutic agent, is believed to cause treatment failure in over $90 \%$ of MBC patients. Although patients generally have a favorable initial response to taxane regimens, the rapid development of resistance to taxanes is prevalent [52]. This prompted us to examine whether Anthos could 
chemosensitize resistant BC cells. Our data indicate that Anthos enhanced the efficacy of PAC by reducing its $\mathrm{IC}_{50}$ value, thus suggesting its chemosensitizing ability against PAC-induced drug resistance in MDA-MB-231Tx cells.

After induction of resistance to a single class of anti-cancer agents, tumor cells may subsequently exhibit resistance to other structurally unrelated drugs, which is referred to as "cross-resistance" or "multidrug resistance" (MDR). Overexpression of drug transporter proteins, such as PgP, MRP1, and BCRP has been reported to play a major role in MDR. Additionally, activation of the NF- $\mathrm{KB}$ signaling pathway is a common phenomenon in several PAC-resistant cancers, including TNBCs [53]. In this report, we observed multiple targets of Anthos to overcome acquired resistance to PAC in BC cells; first, by inhibition of NF- $\mathrm{KB}$ signaling molecules and, second, by reversal of MDR resistance markers expression levels. Anthos also phosphorylates $\mathrm{TNF} \alpha$-induced $\mathrm{I} \kappa \mathrm{B} \alpha$, followed by its degradation, suggesting a role of Anthos in modulating the NF- $\mathrm{KB}$ signaling pathway. Moreover, Anthos treatment decreased the protein levels of IKK $\alpha$, IKK $\beta$, and $\mathrm{p}-\mathrm{IKK} \alpha / \beta$. As the phosphorylation of IKK $\alpha$ and IKK $\beta$ is associated with IKKs [30], these data suggest that Anthos cause apoptosis by stimulating IkB $\alpha$, leading to NF- $\mathrm{B} B$ survival pathway obstruction. Further, Anthos-induced suppression of NF- $\mathrm{kB}$ activity could potentiate the effect of PAC, as observed by a synergistic effect under their combination. Similar activity has also been reported with another polyphenol, resveratrol, which inhibits TPA-induced phosphorylation of $I \kappa B \alpha$ and subsequent p65 nuclear translocation in mouse skin by blocking $\operatorname{IKK} \alpha$ and IKK $\beta$ [54].

We investigated the chemosensitizing potential of an Anthos and PAC combination to inhibit the growth and metastasis of PAC-resistant MBC orthoxenografts. PAC combined with Anthos showed strong anti-tumor efficacy. However, we noted the lack of effectiveness of treatment with Anthos alone in this model. This was somewhat expected, due to the aggressiveness of the tumor growth rate of MDA-MB-231Tx orthoxenografts. A similar finding of synergistic activity with Anthos has been observed against a lung cancer tumor xenograft [6]. These data confirm that the Anthos-PAC combination is effective and can synergistically inhibit the growth of drug-resistant BC.

\section{Conclusions}

In this report, we provided mechanistic insights into the mode of action of berry Anthos leading to the growth inhibition and apoptosis of TNBC cells. The bilberry bioactives (Anthos) inhibited the growth and metastasis of $\mathrm{BC}$ and chemosensitized the cells to the standard chemo drug, PAC, serving as an effective strategy for the management of metastatic TNBC. We gained mechanistic insights by examining multiple targets associated with cell proliferation, apoptosis, inflammation, invasion, and metastasis. For the first time, we report the significant inhibition of orthotopic TNBC (MDA-MB-231) xenograft tumor growth and lymph node metastasis through the oral administration of berry Anthos. Furthermore, our findings indicated the chemosensitizing ability of the Anthos against PAC-resistant $\mathrm{BC}$ cells, by inhibiting the expression of drug transporter markers. A synergistic effect between PAC and the Anthos was observed, with significant tumor growth reduction $(>60 \%)$ in a PAC-resistant MDA-MB-231Tx xenograft. The effectiveness of Anthos will likely increase when delivered in milk exosomal formulations, as has been demonstrated against lung cancer [26] and ovarian cancer [22]. Together, these tumor inhibition and mechanistic insights will be valuable for clinical translation of Anthos, either alone or as adjuvant to chemotherapy, for the treatment of $\mathrm{BC}$ patients.

Supplementary Materials: The following are available online at https:/ / www.mdpi.com/article / 10.3390 / cancers13246248/s1, Table S1: Gross examination of macro-metastasis following treatment with Anthos in an orthotopic model of TNBC, Figure S1: Effect of Anthocyanidins on normal epithelial keratinocytes cells, Figure S2: Densitometry data of blots in Figure 1a, Figure S3: Densitometry data of blots in Figure 1e, Figure S4: Effect of Anthos on cell-cycle progression in TNBC cells, Figure S5: Densitometry data of blots in Figure 2a, Figure S6: Densitometry data of blots in Figure 2b, Figure S7: Densitometry data of blots in Figure 2e, Figure S8: Anthos inhibits phosphorylation of IkBa dose- 
dependently in TNFa-induced TNBC cells, Figure S9: Densitometry data of blots in Figure 3d, Figure S10: Development of orthotopic models on TNBC in Athymic nude and NOD-skid mice, Figure S11: Anthos inhibits phosphorylation of IkBa dose-dependently in drug-resistant MDA-MB231 cells, Figure S12: Densitometry data of blots in Figure 6d, Figure S13: Original Western Blot of Figures $1 d, 2 e$ and $3 d$.

Author Contributions: Conceptualization: R.C.G. and R.M.; methodology: R.M. and F.A.; validation: R.M. and F.A.; investigation: R.M., F.A., S.N.R., A.K.A., N.T. and J.J.; resources: R.C.G. and R.M.; writing-original draft preparation: R.M. and F.A.; writing-review and editing: R.C.G., R.M. and F.A.; supervision: R.C.G., R.M. and F.A.; Formal analysis: S.N.R.; funding acquisition: R.C.G. All authors have read and agreed to the published version of the manuscript.

Funding: This work was supported by the DoD grant W81XWH-14-1-0269 and, in part, Agnes Brown Duggan Endowment (to R.C.G.).

Institutional Review Board Statement: All animals were maintained according to the Institutional Animal Care and Use Committee (IACUC) guidelines (IACUC \# 17041; approval date: 1 June 2017) of the University of Louisville, Louisville, KY, USA.

Informed Consent Statement: Not applicable.

Data Availability Statement: The data presented in this study are available on request from the corresponding author. The data are not publicly available due to privacy.

Acknowledgments: This work was supported by the DoD grant W81XWH-14-1-0269 (to R.C.G. and R.M.) and, in part, Agnes Brown Duggan Endowment (to R.C.G.). The authors thank Raghuram Kandimalla and Disha Moholkar for their help in Western blot analysis using ImageJ.

Conflicts of Interest: The authors declare no conflict of interest.

\section{References}

1. Siegel, R.L.; Miller, K.D.; Fuchs, H.E.; Jemal, A. Cancer Statistics, 2021. CA Cancer J. Clin. 2021, 71, 7-33. [CrossRef] [PubMed]

2. Pulido, C.; Vendrell, I.; Ferreira, A.R.; Casimiro, S.; Mansinho, A.; Alho, I.; Costa, L. Bone metastasis risk factors in breast cancer. Ecancermedicalscience 2017, 11, 715. [CrossRef] [PubMed]

3. Available online: http://www.breast-cancer.ca/survival-statistics/breast-cancer-metastasis.htm (accessed on 1 May 2012).

4. Dolle, J.M.; Daling, J.R.; White, E.; Brinton, L.A.; Doody, D.R.; Porter, P.L.; Malone, K.E. Risk factors for triple-negative breast cancer in women under the age of 45 years. Cancer Epidemiol. Prev. Biomark. 2009, 18, 1157-1166. [CrossRef] [PubMed]

5. Onitilo, A.A.; Engel, J.M.; Greenlee, R.T.; Mukesh, B.N. Breast cancer subtypes based on ER/PR and Her2 expression: Comparison of clinicopathologic features and survival. Clin. Med. Res. 2009, 7, 4-13. [CrossRef]

6. Kausar, H.; Jeyabalan, J.; Aqil, F.; Chabba, D.; Sidana, J.; Singh, I.P.; Gupta, R.C. Berry anthocyanidins synergistically suppress growth and invasive potential of human non-small-cell lung cancer cells. Cancer Lett. 2012, 325, 54-62. [CrossRef]

7. Kuo, M.T. Roles of multidrug resistance genes in breast cancer chemoresistance. Adv. Exp. Med. Biol. 2007, 608, 23-30.

8. Rivera, E.; Gomez, H. Chemotherapy resistance in metastatic breast cancer: The evolving role of ixabepilone. Breast Cancer Res. 2010, 12 (Suppl. 2), S2. [CrossRef]

9. Ghosh, D.; Konishi, T. Anthocyanins and anthocyanin-rich extracts: Role in diabetes and eye function. Asia Pac. J. Clin. Nutr. 2007, 16, 200-208.

10. Wang, L.S.; Stoner, G.D. Anthocyanins and their role in cancer prevention. Cancer Lett. 2008, 269, 281-290. [CrossRef]

11. Bagchi, D.; Sen, C.K.; Bagchi, M.; Atalay, M. Anti-angiogenic, antioxidant, and anti-carcinogenic properties of a novel anthocyaninrich berry extract formula. Biochemistry 2004, 69, 75-80. [CrossRef]

12. Bornsek, S.M.; Ziberna, L.; Polak, T.; Vanzo, A.; Ulrih, N.P.; Abram, V.; Tramer, F.; Passamonti, S. Bilberry and blueberry anthocyanins act as powerful intracellular antioxidants in mammalian cells. Food Chem. 2012, 134, 1878-1884. [CrossRef]

13. Basu, A.; Du, M.; Leyva, M.J.; Sanchez, K.; Betts, N.M.; Wu, M.; Aston, C.E.; Lyons, T.J. Blueberries decrease cardiovascular risk factors in obese men and women with metabolic syndrome. J. Nutr. 2010, 140, 1582-1587. [CrossRef]

14. Faria, A.; Pestana, D.; Teixeira, D.; de Freitas, V.; Mateus, N.; Calhau, C. Blueberry anthocyanins and pyruvic acid adducts: Anticancer properties in breast cancer cell lines. Phytother. Res. 2010, 24, 1862-1869. [CrossRef]

15. Harris, G.K.; Gupta, A.; Nines, R.G.; Kresty, L.A.; Habib, S.G.; Frankel, W.L.; LaPerle, K.; Gallaher, D.D.; Schwartz, S.J.; Stoner, G.D. Effects of lyophilized black raspberries on azoxymethane-induced colon cancer and 8-hydroxy-2'-deoxyguanosine levels in the Fischer 344 rat. Nutr. Cancer 2001, 40, 125-133. [CrossRef]

16. Stoner, G.D.; Wang, L.S.; Seguin, C.; Rocha, C.; Stoner, K.; Chiu, S.; Kinghorn, A.D. Multiple berry types prevent N-nitrosomethylbenzylamine-induced esophageal cancer in rats. Pharm. Res. 2010, 27, 1138-1145. [CrossRef]

17. Stoner, G.; Hasson, H.; Sardo, C.; Wang, L.; Pearl, D.; Buchta, A.; Burke, C. Regression of rectal polyps in familial adenomatous polyposis patients with freeze-dried black raspberries. Cancer Prev. Res. 2012, 1 (Suppl. 7), PR-14. 
18. Aiyer, H.S.; Srinivasan, C.; Gupta, R.C. Dietary berries and ellagic acid diminish estrogen-mediated mammary tumorigenesis in ACI rats. Nutr. Cancer 2008, 60, 227-234. [CrossRef]

19. Aiyer, H.S.; Gupta, R.C. Berries and ellagic acid prevent estrogen-induced mammary tumorigenesis by modulating enzymes of estrogen metabolism. Cancer Prev. Res. 2010, 3, 727-737. [CrossRef]

20. Srivani Ravoori, H.K.; Aqil, F.; Ramesh, C.G. Distinct molecular targets of blueberry and black raspberry in breast cancer prevention. In Proceedings of the American Association of Cancer Research, Washington, DC, USA, 17-21 April 2010.

21. Adams, L.S.; Phung, S.; Yee, N.; Seeram, N.P.; Li, L.; Chen, S. Blueberry phytochemicals inhibit growth and metastatic potential of MDA-MB-231 breast cancer cells through modulation of the phosphatidylinositol 3-kinase pathway. Cancer Res. 2010, 70, 3594-3605. [CrossRef]

22. Aqil, F.; Jeyabalan, J.; Agrawal, A.K.; Kyakulaga, A.H.; Munagala, R.; Parker, L.; Gupta, R.C. Exosomal delivery of berry anthocyanidins for the management of ovarian cancer. Food Funct. 2017, 8, 4100-4107. [CrossRef]

23. Mudd, A.M.; Gu, T.; Munagala, R.; Jeyabalan, J.; Egilmez, N.K.; Gupta, R.C. Chemoprevention of Colorectal Cancer by Anthocyanidins and Mitigation of Metabolic Shifts Induced by Dysbiosis of the Gut Microbiome. Cancer Prev. Res. 2020, 13, 41-52. [CrossRef]

24. Gupta, R. Methods for Isolation of Bulk Anthocyanidins and Other Bioactives. U.S. Patent US8987481 B1, 14 March 2015.

25. Munagala, R.; Aqil, F.; Jeyabalan, J.; Gupta, R.C. Bovine milk-derived exosomes for drug delivery. Cancer Lett. 2016, 371, 48-61. [CrossRef]

26. Munagala, R.; Aqil, F.; Jeyabalan, J.; Agrawal, A.K.; Mudd, A.M.; Kyakulaga, A.H.; Singh, I.P.; Vadhanam, M.V.; Gupta, R.C. Exosomal formulation of anthocyanidins against multiple cancer types. Cancer Lett. 2017, 393, 94-102. [CrossRef]

27. Szakacs, G.; Paterson, J.K.; Ludwig, J.A.; Booth-Genthe, C.; Gottesman, M.M. Targeting multidrug resistance in cancer. Nat. Rev. Drug Discov. 2006, 5, 219-234. [CrossRef]

28. Kang, H.J.; Lee, S.H.; Price, J.E.; Kim, L.S. Curcumin suppresses the paclitaxel-induced nuclear factor- $\mathrm{kB}$ in breast cancer cells and potentiates the growth inhibitory effect of paclitaxel in a breast cancer nude mice model. Breast J. 2009, 15, 223-229. [CrossRef]

29. Huang, Y.; Fang, Y.; Dziadyk, J.M.; Norris, J.S.; Fan, W. The possible correlation between activation of NF-кB/IкB pathway and the susceptibility of tumor cells to paclitaxel-induced apoptosis. Oncol. Res. 2002, 13, 113-122.

30. Karin, M.; Ben-Neriah, Y. Phosphorylation meets ubiquitination: The control of NF-[k]B activity. Annu. Rev. Immunol. 2000, 18, 621-663. [CrossRef]

31. Dunnwald, L.K.; Rossing, M.A.; Li, C.I. Hormone receptor status, tumor characteristics, and prognosis: A prospective cohort of breast cancer patients. Breast Cancer Res. 2007, 9, R6. [CrossRef] [PubMed]

32. Aqil, F.; Jeyabalan, J.; Munagala, R.; Singh, I.P.; Gupta, R.C. Prevention of hormonal breast cancer by dietary jamun. Mol. Nutr. Food Res. 2016, 60, 1470-1481. [CrossRef] [PubMed]

33. Aqil, F.; Gupta, A.; Munagala, R.; Jeyabalan, J.; Kausar, H.; Sharma, R.J.; Singh, I.P.; Gupta, R.C. Antioxidant and antiproliferative activities of anthocyanin/ellagitannin-enriched extracts from Syzygium cumini L. (Jamun, the Indian Blackberry). Nutr. Cancer 2012, 64, 428-438. [CrossRef] [PubMed]

34. Yi, L.; Chen, C.Y.; Jin, X.; Mi, M.T.; Yu, B.; Chang, H.; Ling, W.H.; Zhang, T. Structural requirements of anthocyanins in relation to inhibition of endothelial injury induced by oxidized low-density lipoprotein and correlation with radical scavenging activity. FEBS Lett. 2010, 584, 583-590. [CrossRef]

35. Lazze, M.C.; Savio, M.; Pizzala, R.; Cazzalini, O.; Perucca, P.; Scovassi, A.I.; Stivala, L.A.; Bianchi, L. Anthocyanins induce cell cycle perturbations and apoptosis in different human cell lines. Carcinogenesis 2004, 25, 1427-1433. [CrossRef]

36. Khan, N.; Adhami, V.M.; Mukhtar, H. Apoptosis by dietary agents for prevention and treatment of cancer. Biochem. Pharmacol. 2008, 76, 1333-1339. [CrossRef]

37. Androic, I.; Kramer, A.; Yan, R.; Rodel, F.; Gatje, R.; Kaufmann, M.; Strebhardt, K.; Yuan, J. Targeting cyclin B1 inhibits proliferation and sensitizes breast cancer cells to taxol. BMC Cancer 2008, 8, 391. [CrossRef]

38. Pucci, B.; Kasten, M.; Giordano, A. Cell cycle and apoptosis. Neoplasia 2000, 2, 291-299. [CrossRef]

39. Bin Hafeez, B.; Asim, M.; Siddiqui, I.A.; Adhami, V.M.; Murtaza, I.; Mukhtar, H. Delphinidin, a dietary anthocyanidin in pigmented fruits and vegetables: A new weapon to blunt prostate cancer growth. Cell Cycle 2008, 7, 3320-3326. [CrossRef]

40. Geraets, L.; Moonen, H.J.; Brauers, K.; Wouters, E.F.; Bast, A.; Hageman, G.J. Dietary flavones and flavonoles are inhibitors of poly(ADP-ribose)polymerase-1 in pulmonary epithelial cells. J. Nutr. 2007, 137, 2190-2195. [CrossRef]

41. Lin, B.W.; Gong, C.C.; Song, H.F.; Cui, Y.Y. Effects of anthocyanins on the prevention and treatment of cancer. Br. J. Pharmacol. 2017, 174, 1226-1243. [CrossRef]

42. Sarkar, D.K.; Jana, D.; Patil, P.S.; Chaudhari, K.S.; Chattopadhyay, B.K.; Chikkala, B.R.; Mandal, S.; Chowdhary, P. Role of NF-kB as a Prognostic Marker in Breast Cancer: A Pilot Study in Indian Patients. Indian J. Surg. Oncol. 2013, 4, 242-247. [CrossRef]

43. Wu, Y.; Zhou, B.P. TNF- $\alpha$ /NF-kB/Snail pathway in cancer cell migration and invasion. Br. J. Cancer 2010, 102, 639-644. [CrossRef]

44. Kumar, M.; Allison, D.F.; Baranova, N.N.; Wamsley, J.J.; Katz, A.J.; Bekiranov, S.; Jones, D.R.; Mayo, M.W. NF-кB regulates mesenchymal transition for the induction of non-small cell lung cancer initiating cells. PLoS ONE 2013, 8, e68597. [CrossRef]

45. Huber, M.A.; Azoitei, N.; Baumann, B.; Grunert, S.; Sommer, A.; Pehamberger, H.; Kraut, N.; Beug, H.; Wirth, T. NF-kB is essential for epithelial-mesenchymal transition and metastasis in a model of breast cancer progression. J. Clin. Investig. 2004, 114, 569-581. [CrossRef] 
46. Barbera, M.J.; Puig, I.; Dominguez, D.; Julien-Grille, S.; Guaita-Esteruelas, S.; Peiro, S.; Baulida, J.; Franci, C.; Dedhar, S.; Larue, L.; et al. Regulation of Snail transcription during epithelial to mesenchymal transition of tumor cells. Oncogene 2004, 23, 7345-7354. [CrossRef]

47. Ouanouki, A.; Lamy, S.; Annabi, B. Anthocyanidins inhibit epithelial-mesenchymal transition through a TGF $\beta /$ Smad2 signaling pathway in glioblastoma cells. Mol. Carcinog. 2017, 56, 1088-1099. [CrossRef]

48. Zhang, L.; Wang, X.; Lai, M. Modulation of epithelial-to-mesenchymal cancerous transition by natural products. Fitoterapia 2015, 106, 247-255. [CrossRef]

49. Lu, J.N.; Lee, W.S.; Kim, M.J.; Yun, J.W.; Jung, J.H.; Yi, S.M.; Jeong, J.H.; Kim, H.J.; Choi, Y.H.; Kim, G.S.; et al. The inhibitory effect of anthocyanins on Akt on invasion and epithelial-mesenchymal transition is not associated with the anti-EGFR effect of the anthocyanins. Int. J. Oncol. 2014, 44, 1756-1766. [CrossRef]

50. Jeyabalan, J.; Aqil, F.; Munagala, R.; Annamalai, L.; Vadhanam, M.V.; Gupta, R.C. Chemopreventive and therapeutic activity of dietary blueberry against estrogen-mediated breast cancer. J. Agric. Food Chem. 2014, 62, 3963-3971. [CrossRef]

51. Cleator, S.; Heller, W.; Coombes, R.C. Triple-negative breast cancer: Therapeutic options. Lancet Oncol. 2007, 8, 235-244. [CrossRef]

52. Gluz, O.; Liedtke, C.; Gottschalk, N.; Pusztai, L.; Nitz, U.; Harbeck, N. Triple-negative breast cancer-Current status and future directions. Ann. Oncol. 2009, 20, 1913-1927. [CrossRef]

53. Das, K.C.; White, C.W. Activation of NF-кB by antineoplastic agents. Role of protein kinase C. J. Biol. Chem. 1997, 272, 14914-14920. [CrossRef]

54. Surh, Y.J.; Na, H.K. NF-кB and Nrf2 as prime molecular targets for chemoprevention and cytoprotection with anti-inflammatory and antioxidant phytochemicals. Genes Nutr. 2008, 2, 313-317. [CrossRef] [PubMed] 